This PDF is a selection from a published volume from the National Bureau of Economic Research

Volume Title: Analyses in the Economics of Aging

Volume Author/Editor: David A. Wise, editor

Volume Publisher: University of Chicago Press

Volume ISBN: 0-226-90286-2

Volume URL: http://www.nber.org/books/wise05-1

Publication Date: August 2005

Title: Healthy, Wealthy, and Knowing Where to Live:

Author: Florian Heiss, Michael D. Hurd, Axel H. Boersch-Supan

URL: http://www.nber.org/chapters/c10363 


\section{Healthy, Wealthy, and Knowing Where to Live Trajectories of Health, Wealth, and Living Arrangements among the Oldest Old}

Florian Heiss, Michael D. Hurd, and Axel Börsch-Supan

\subsection{Introduction}

Health, wealth, and where one lives are important, if not the three most important material living conditions. This paper investigates the joint evolution of these three conditions. The elderly reach their early postretirement years in an initial status that is characterized by housing wealth, nonhousing bequeathable wealth, annuity income, health status, and family connections. The broad goal of this paper is to describe the trajectories of health, wealth, and living arrangements in older age that start from this initial state; to understand how the trajectories of health status, wealth position, and living arrangements are interrelated with each other; and to be able to predict how health and living arrangements will evolve when economic and other conditions change.

Projecting the trajectories of health, wealth, and living arrangements into the future is not a trivial task. Simple cross-sectional statistics may lead one astray. For instance, we find in cross-section data an increasing propensity for elderly individuals to live with others, especially their children (Börsch-Supan 1988, 1990; Ellwood and Kane 1990; Wolf 1995). But the living arrangements of the oldest may not be a good prediction of the

Florian Heiss is a research associate of the Mannheim Research Institute for the Economics of Aging. Michael D. Hurd is a senior economist at RAND, director of the RAND Center for the Study of Aging, and a research associate of the National Bureau of Economic Research (NBER). Axel Börsch-Supan is a professor of economics at the University of Mannheim, director of the Mannheim Research Institute for the Economics of Aging, and a research associate of the NBER.

We thank Steve Venti for helpful comments. Financial support was provided by the National Institute on Aging (NIA) grant number R01 AG16772, through the NBER. We are also grateful for financial support by the State of Baden-Württemberg and the German Insurers Association (GDV). 
living arrangement of those just entering their postretirement years. Because of differences in the economic resources of the cohorts, the younger cohorts are likely to reach the oldest ages with more resources, and, assuming that living alone is a superior good, they will have a greater propensity to live alone (Börsch-Supan, Kotlikoff, and Morris 1991; McGarry and Schoeni 1998). Furthermore, the observed age profiles of living arrangements are not followed by any person or couple: because the poorest in a cohort die sooner than the better off, the average value of wealth, health, or housing of a cohort will increase with age even in the absence of any systematic change at the individual or household level.

Yet understanding the age path and determinants of living arrangements is important both from a social point of view and from a scientific point of view. For example, as shown in table 8.1, living with other family members is a substantial economic resource that is frequently ignored in assessing the economic well-being of the oldest old (Cox and Raines 1985; Kotlikoff and Morris 1989; Sloan and Shayne 1993; Grad 1994). This is evidenced, for example, by a much lower poverty rate of elderly widows living with other family members as compared to the poverty rate of widows in the general population.

The frail elderly receive care when living with others, either with a spouse or with children, that can substitute for market-purchased care or for longterm care provided thought public programs such as Medicaid (Wolf 1984, 1994; McGarry and Schoeni 1998). There is even some suggestion that living arrangements affect the health of the elderly person: apparently being cared for in the home of a family member is better for health outcomes than institutionally provided long-term care (Moon 1983; Horowitz 1985; Stone, Cafferata, and Sangl 1987).

From a scientific point of view, the main model of consumption and saving by the elderly, the life-cycle model, is incomplete if it does not recognize the additional resources that may be transferred through joint living (Hurd 1990). For example, it is plausible that the magnitude of such transfers is greater than measured cash transfers to an independently living parent. There are many other examples of close relationships among living arrangements, health, and economic status. For instance, an unexpected

Table 8.1

Poverty and living arrangements: Poverty rates (\%)

\begin{tabular}{lccc}
\hline & & \multicolumn{2}{c}{ Nonmarried women } \\
\cline { 3 - 4 } Age range & Couples & Live with other family members & Live with no family members \\
\hline $65-74$ & 6 & 12 & 24 \\
$75-84$ & 7 & 12 & 28 \\
85 or over & 10 & 10 & 31 \\
\hline
\end{tabular}

Source: Grad, 1994. 
decline in wealth may trigger a transition to joint living to conserve resources. A decline in health may cause a transition to joint living or into a nursing home for the provision of care. The probability of either transition would be modified by other important covariates. In the first case, health status could act through differences in life expectancy or need for care. In the second case, economic status would be important because of the possibility of purchasing care in the market. In both cases the number and location of children would be important as well as their sex and economic status. For example, a well-to-do son may prefer to transfer cash for the market purchase of services, whereas a daughter may prefer to provide the services directly.

These examples suggest that living arrangements and well-being derived from health and economic status are closely related and that their evolution over the life course should be studied jointly. This is the aim of this paper. We study the relationships among living arrangements, health, and economic status using a microeconometric approach similar to what is known as vector autoregressions (VARs) in the macroeconomics literature.

The economic determinants of living arrangements have had relatively little research attention compared with other aspects of the well-being of the oldest old. For example, the early analyses of the Study of Asset and Health Dynamics of the Oldest Old (AHEAD) did not explicitly consider the choice of living arrangements (Henretta et al. 1997; Wolf, Freedman, and Soldo 1997), although the importance of family care for elderly parents was stressed in both articles. ${ }^{1}$ Because research on the economic determinants of living arrangements is not well developed, we are not adequately equipped to understand the decline in the propensity to coreside with children that began in the late 1970s and early 1980s (Börsch-Supan 1990; Ellwood and Kane 1990; Kotlikoff and Morris 1990; Wolf 1995; Costa 1997). It is important to understand how this decrease came about and whether it is related to changes in the economic circumstances of the elderly. Specifically, we would like to understand whether the decrease is related to a change in family linkages or to the increase in Social Security wealth and Medicare benefits, as suggested by Wolf (1995), Costa (1997), and McGarry and Schoeni (1998). This understanding would help to assess the likely impact of future changes in the generosity of Social Security and Medicare benefits, as well as the potential impact of changes in the extent of family links when the members of the baby boom generation will need to support their elderly parents.

We also lack reliable knowledge of some fundamental facts. For example, it is controversial whether the elderly downsize housing in old age and extract equity for nonhousing consumption (Ai et al. 1990; Venti and Wise 1990, 2001; Sheiner and Weil 1992). We do not know the quantitative 
importance of the progression of care from living independently to coresiding with children to living in a nursing home. We do not know whether coresiding with children changes bequest behavior. The AHEAD data on which this paper is based are well suited to start answering these questions.

Because many fundamental facts are still unclear, our research will proceed in steps. In this paper, we will begin with establishing a reliable account of how living arrangements, health, and economic status evolve as the elderly age and proceed by linking these trajectories to observable covariates. In this sense, this paper is mainly descriptive, although it does use multidimensional regression methods. It extends the analysis by Hurd, McFadden, and Merrill (1998) by a third dimension - namely, living arrangements - and applies a richer methodology. Further research will take account of the considerable heterogeneity in our sample. Accounting for the heterogeneity in order to properly isolate the effects of economic and other covariates will require more advanced econometric methods (e.g., the MPMNP model in Börsch-Supan et al. 1992 and the MIMIC model in Börsch-Supan, McFadden, and Schnabel 1996). Once we have precise estimates of the influence that these covariates exert on living arrangements, health, and economic status, we can compare our estimated coefficients and predicted trajectories to those generated by leading behavioral models. This will be the subject of further research.

The paper is structured as follows. Section 8.2 describes the AHEAD data and presents some central descriptive statistics. Section 8.3 develops our methodology to estimate transition probabilities based on relatively simple first-order Markov processes. Section 8.4 describes our estimation results. Section 8.5 constructs and interprets predicted trajectories of health, wealth, and living arrangements that start at age seventy and go through age ninety. Section 8.6 focuses on a specific aspect of these trajectories, the reduction in home ownership. Section 8.7 briefly concludes.

\subsection{Data}

Our work is based on the first four waves of AHEAD. This study is particularly well suited for the purposes of this paper because one module was specifically designed to study living arrangements, intergenerational transfers of both money and time help, and how they relate to health and economic status.

The AHEAD survey is a biennial panel that is being collected by the Survey Research Center at the University of Michigan. It is now a part of the U.S. Health and Retirement Survey (HRS). The AHEAD study is nationally representative of the cohorts born in 1923 or earlier with oversampling of blacks, Hispanics, and Floridians. We will focus on age-eligible individuals: that is, those persons from the cohorts of 1923 or earlier who were approximately aged seventy or older at baseline in 1993. 
The AHEAD panel is the first data set that permits combining the study of asset decumulation and health with the study of living arrangements of the oldest old. In fact, AHEAD was specifically designed to enable a comprehensive understanding of how health and wealth status affect the wellbeing of the elderly as they age (Soldo et al. 1997). For instance, the AHEAD survey has much more reliable measures of the wealth of the elderly than the data sets employed in previous analyses, plus more extensive health information, and the AHEAD data identify in a better way family links, in particular the economic resources of the children who, at some point in the future, may coreside with the elderly person.

While the AHEAD data start with a sample of the noninstitutionalized, the panel tracks the elderly when they enter a nursing home or similar institutions. We can observe asset changes at the time of this transition. The AHEAD data supply information on changes in the economic status of children and parents, together with changes in health and changes in housing and living arrangements. The AHEAD data contain a proxy interview after the death of the respondent such that the living arrangement at the time of death can be ascertained.

The AHEAD survey as well as the other cohorts in the HRS have cores with questions in the following broad classes: employment (current and former jobs); health measures, including self-assessed health, performance measures, disease conditions, cognition, mood, and activity of daily living (ADL) and instrumental activity of daily living (IADL) limitations; income and assets; family structure and intergenerational transfers, of both financial help and time help; housing; insurance; and pensions.

In addition to the core content, the survey obtained a roster of the extended family including a number of characteristics of each child of the AHEAD respondent. Of importance for this paper, the characteristics include education, income, home ownership, marital status, and parental status. Children from the family roster were linked during the computerassisted interview to both financial help and time help given to the AHEAD respondent. This linkage will permit analyses of motivations for transfers such as whether the less well-to-do child receives greater financial transfers from the AHEAD parent and if, in turn, that child provides greater time help. Information about the beneficiaries of life insurance and of wills was obtained. Anticipated bequests were measured by questions about the subjective probability of giving a bequest and its magnitude. Considerable information about housing was obtained at baseline including adaptations of housing to disabilities. This is important since such adaptations offer an alternative to moving when health deteriorates.

The AHEAD survey contains a psychometric battery with questions asking for subjective beliefs such as "Using any number from 0 to 100 , where 0 means that you think there is absolutely no chance and 100 means that you think the event is absolutely sure to happen, what do you think are 
the chances that you will have to give major financial help to family members during the next ten years? . . that you will receive major financial help from family members during the next ten years? . . that you will move to a nursing home over the next five years?" In a similar way, subjects who were seventy to seventy-four years old at baseline were asked to give their subjective survival probability to age eighty-five; subjects who were seventy-five to seventy-nine were asked their survival probability to age ninety, and so forth. These subjective survival probabilities are highly predictive of mortality between waves 1 and 2 (Hurd and McFadden 1998).

As in all household-level data sets, the frequency of missing asset items is fairly large in AHEAD. However, AHEAD (as well as HRS) made extensive use of bracketing techniques that converted nonresponses on asset amounts to intervals by a series of questions about the range of the asset amount (Smith 1997). Because the distribution of financial assets in particular is highly skewed, these techniques are very valuable in reducing imputation error. We have spent considerable effort developing and implementing methods to impute missing asset items based on the brackets (Hoynes, Hurd, and Chand 1997). The methods involve using bracket information and covariates in a way that conserves the multivariate distribution of assets and other characteristics. The construction of wealth quartiles in this paper rests on this method.

In the first AHEAD wave in 1993, 8,222 interviews were obtained. We restrict our analysis to those individual who were born before 1924, ignoring 779 younger spouses. In waves 2 (1995) through 4 (1999), no interview could be obtained for 865 of the remaining respondents, leaving 6,578 for our analysis. By wave 4, 2,508 (38 percent) of those respondents have died. In total, 21,296 interviews (on average, 3.2 interviews per respondent) and 14,718 transitions ( 2.2 per respondent) are available for the analysis.

Table 8.2 shows descriptive statistics of the most important variables for our study. The average age is eighty years, and between two waves 14.6 percent of the respondents die on average. Sixty-two percent of the respondents are female, reflecting the higher life expectancy. Forty-six percent of the respondents are married -85 percent of the others are widowed, the others are either divorced or never married. Seventy-two percent of the interviewees own their home. Seventy-five percent live on their own, and 19 percent coreside with others - mostly with their children and/or grandchildren. Since in wave 1 only noninstitutionalized individuals were interviewed, only respondents who move to nursing homes after that are followed there. This results in only 4.3 percent of interviews in nursing homes. The average respondent has 2.8 children, 1.4 of whom are female. On average, 1.9 of these children are married and 2.3 are single.

Figure 8.1 shows age paths of the most important variables of our analysis. They represent simple averages of these variables for the respondents 


\begin{tabular}{lc}
\hline Variable & Mean \\
\hline Age & 80.29 \\
Mortality & 0.146 \\
Female & 0.619 \\
Married & 0.461 \\
Health condition prevalence (heart, stroke, cancer) & 0.506 \\
Health condition incidence & 0.177 \\
Health status & \\
Excellent/Very good & 0.306 \\
Good & 0.303 \\
Fair/Poor & 0.391 \\
Home ownership & 0.721 \\
Living arrangement & \\
Alone & 0.765 \\
With others & 0.192 \\
Nursing home & 0.043 \\
No. of children & \\
Total & 2.780 \\
Female & 1.416 \\
Married & 1.942 \\
With children & 2.345 \\
\hline
\end{tabular}

Source: AHEAD, pooled waves 1-4.
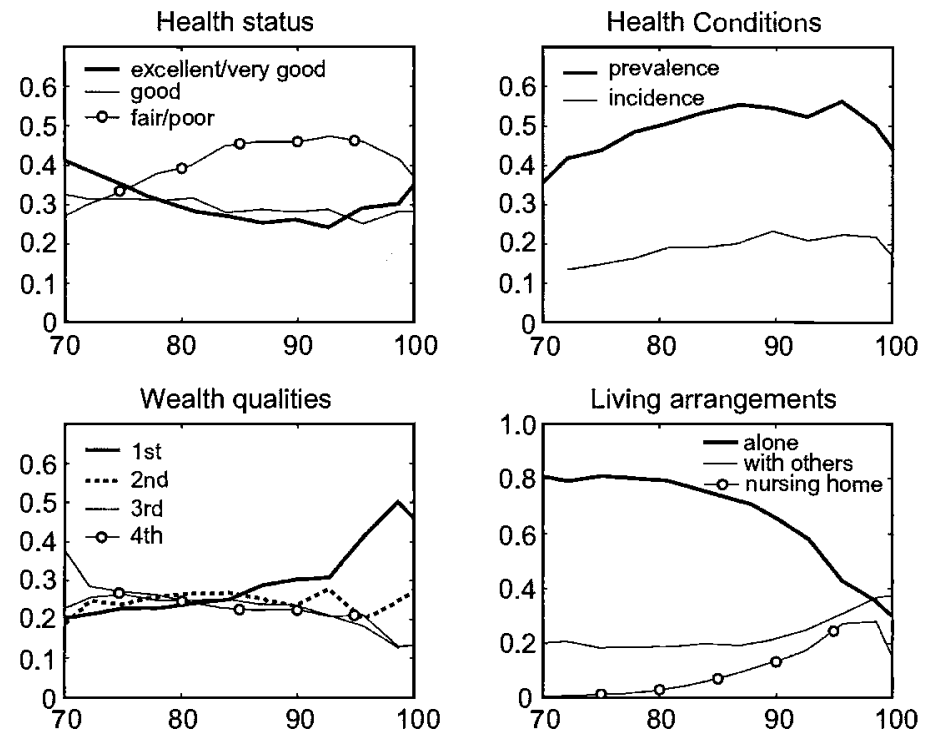

Fig. 8.1 Age patterns in the four pooled cross sections 1993-99

Source: Pooled AHEAD waves 1-4. 
of the respective age in a pooled cross section of the AHEAD data, waves 1 through 4 . Three effects drive the shape of these curves. The first is cohort differences. The second effect is the evolution of the variables over the life course: older respondents report a worse health status and face a larger threat of health condition incidents. The third effect is differential mortality. It affects the mean characteristics of the (surviving) respondents. This third effect seems to dominate the health measures for the very old: health status and health condition prevalence are actually more favorable for the (very few) centenarians than for those aged around ninety. The share of the respondents in the highest wealth quartiles gradually decreases in the age, whereas the rises of the share of the poorest quartile seems to be more pronounced for those aged eighty-five and above. This is the same age group for which the share of respondents living alone decreases dramatically and both nursing homes and coresidence become important alternatives.

\subsection{Estimation of the Transition Probabilities}

Health, wealth, housing, and living arrangements are multidimensional concepts. We analyze the joint evolution of the most important dimensions of health, wealth, and living arrangements of elderly Americans. These dimensions are our state variables and comprise the following characteristics:

- Mortality

- Self-reported health status

- Prevalence and incidences of three major health conditions (heart condition, stroke, cancer)

- Wealth quartile (sum of real and financial wealth)

- Owner-occupancy

- Living arrangements (coresidence and nursing homes)

Table 8.3 gives an overview of these state variables and their possible states.

The joint evolution of the state variables is presumably quite complex. We chose a simple strategy to identify basic patterns. We do not aim at pre-

Table 8.3

State variables

\begin{tabular}{|c|c|c|c|c|}
\hline Variable & State 1 & State 2 & State 3 & State 4 \\
\hline Mortality & Alive & Dead & & \\
\hline Health condition prevalence & Yes & No & & \\
\hline Health condition incidence & Yes & No & & \\
\hline Health status & Excellent/Very good & Good & Fair/Poor & \\
\hline Wealth quartile & 1st & 2 nd & $3 \mathrm{rd}$ & 4 th \\
\hline Ownership & Yes & No & & \\
\hline Living arrangement & Alone & With others & Nursing home & \\
\hline
\end{tabular}


senting a structural model and attach causal interpretations to our findings. Instead, we interpret our approach as a more sophisticated approach to present descriptive evidence. The model can be interpreted like a VAR common in macroeconometrics:

$$
\mathbf{y}_{t}=A \mathbf{y}_{t-1}+B x_{t}
$$

where $\mathbf{y}$ is a vector of the state or left-hand-side variables detailed in table 8.3 and $x$ represents a set of shift variables. We actually do not estimate a linear relation since most variables in $\mathbf{y}$ are limited dependent in their nature, but it helps to keep the macroeconomic counterpart in mind since our approach shares the same fundamental properties and limitations.

More precisely, a given individual (whose subscript is omitted to ease the notational burden) can assume (almost) each combination of states in table 8.3 at each point in time. Let $a_{t}$ denote whether the individual is alive $\left(a_{t}=\right.$ 1) or not $\left(a_{t}=0\right)$ at time $t$. Let $\mathbf{y}_{1 t}$ through $\mathbf{y}_{6 t}$ indicate the states of the other variables from table 8.3 at time $t$. There are $2 \cdot 2 \cdot 3 \cdot 4 \cdot 2 \cdot 3=288$ combinations of these other states. Let $\mathbf{y}_{t}$ denote an indicator of the state defined as a combination of these six variables. Finally, call $\mathbf{x}_{t}$ a vector of exogenous variables such as age and sex. We are interested in understanding the evolution of the states over time - that is, the probability of the event $a_{t}=$ $a^{*}$ and $y_{t}=y^{*}$ given the history of $y_{t}$ and the explanatory variables $\mathbf{x}_{t}$. We denote this probability by $\operatorname{Pr}\left(a_{t}=a^{*}, \mathbf{y}_{t}=\mathbf{y}^{*} \mid \mathbf{y}_{t-1}, \mathbf{y}_{t-2}, \ldots, \mathbf{x}_{t}\right)$. It is the core explanatory variable.

In this general formulation, it is infeasible to econometrically identify this probability. We therefore have to impose restrictions. As a first step, we impose a first-order Markov structure on our model:

(2) $\operatorname{Pr}\left(a_{t}=a^{*}, \mathbf{y}_{t}=\mathbf{y}^{*} \mid \mathbf{y}_{t-1}, \mathbf{y}_{t-2}, \ldots, \mathbf{x}_{t}\right)=\operatorname{Pr}\left(a_{t}=a^{*}, \mathbf{y}_{t}=\mathbf{y}^{*} \mid \mathbf{y}_{t-1}, \mathbf{x}_{t}\right)$

This is quite restrictive and could be generalized somewhat. But since we only have four waves of panel data, the dynamic structure that we can identify with these data is quite limited. A test of a more general structure such as a second-order Markov model is planned in the future.

Secondly, the estimation of a $288 \times 288$ transition matrix is infeasible with our data (and any other real-world data we can think of). We therefore impose structure on the joint dependencies. We choose a very simple approach by assuming that the outcome probabilities of the state variables are conditionally (on $\mathbf{y}_{t-1}$ and $\mathbf{x}_{t}$ ) independent. This allows us to write

$$
\begin{aligned}
& \operatorname{Pr}\left(a_{t}=a^{*}, \mathbf{y}_{t}=\mathbf{y}^{*} \mid \mathbf{y}_{t-1}, \mathbf{x}_{t}\right) \\
& =\operatorname{Pr}\left(a_{t}=a^{*} \mid \mathbf{y}_{t-1}, \mathbf{x}_{t}\right) \cdot \operatorname{Pr}\left(\mathbf{y}_{1 t}=\mathbf{y}_{1}^{*} \mid \mathbf{y}_{t-1}, \mathbf{x}_{t}, a_{t}=a^{*}\right) \\
& \quad \cdot \operatorname{Pr}\left(\mathbf{y}_{2 t}=\mathbf{y}_{2}^{*} \mid \mathbf{y}_{t-1}, \mathbf{x}_{t}, a_{t}=a^{*}\right) \cdot \ldots \cdot \operatorname{Pr}\left(\mathbf{y}_{6 t}=\mathbf{y}_{6}^{*} \mid \mathbf{y}_{t-1}, \mathbf{x}_{t}, a_{t}=a^{*}\right)
\end{aligned}
$$


An alternative feasible approach would be to model correlations between the different state equations with the help of random effects models similar to Börsch-Supan and others (1992). However, this would increase the computational burden substantially since no closed-form solutions for the likelihood function can be derived for these nonlinear simultaneous models.

In addition, we exploit several "natural" restrictions:

- Death is absorbing.

- Health conditions are absorbing: there is no transition from (health conditions $=$ yes) to (health conditions $=$ no).

- Health conditions are preceded by health incidents: if (health conditions $_{t-1}=$ no), then Prob(health conditions $s_{t}=$ yes) $=$ Prob(health incident $_{t}=$ yes).

Given this structure, the models for the different state variables can be estimated separately. Again, we choose a very convenient approach by assuming conditional independence over time, ignoring the panel structure of our data. This simplifies the analysis even more. In particular, we can simply estimate our models conditional on the first observation for each individual. We specify the separate models as binary logits (health condition incidence, home ownership), ordered logits (health status, wealth quartile), and multinomial logits (living arrangements). Obviously, not a full set of 287 dummy variables for $\mathbf{y}_{t-1}$ is included in the regressions, but simplifications are made. They are described in the following section, which presents our estimation results.

\subsection{Estimation Results}

Given the independent first-order Markov structure, we can estimate transition probabilities for the categorical variables in table 8.3 conditional on lagged left-hand-side and socioeconomic variables. The results from these regressions are shown in table 8.4. Except for the health incidence equation, all equations feature a satisfactory fit, and the signs of the estimated coefficients - where significant-exhibit no surprises.

The first column shows ordered logit estimates for a combined health status/mortality regression. The dependent variable is coded as (1) excellent/very good health, (2) good health, (3) poor/fair health, (4) deceased. Not surprisingly, health deteriorates with increasing age. This effect accelerates in old age, as the additional slope parameters of the age spline are positive. Being female and being married increases self-reported health. The prevalence of serious health conditions (heart condition, stroke, cancer) negatively affects the self-reported health status. A health condition incident since the previous wave dramatically increases mortality probabilities and decreases the self-reported health status. Health status is 


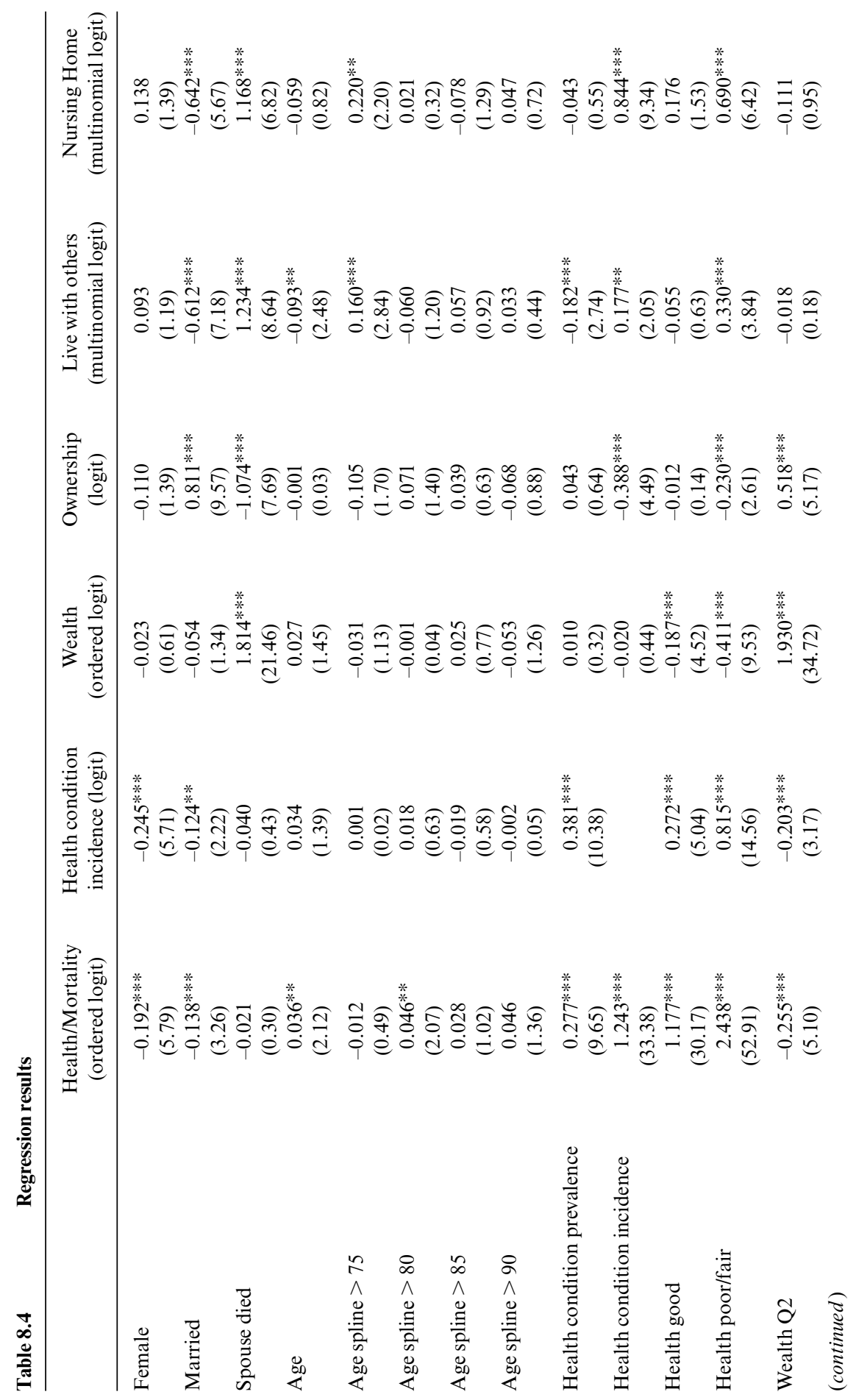




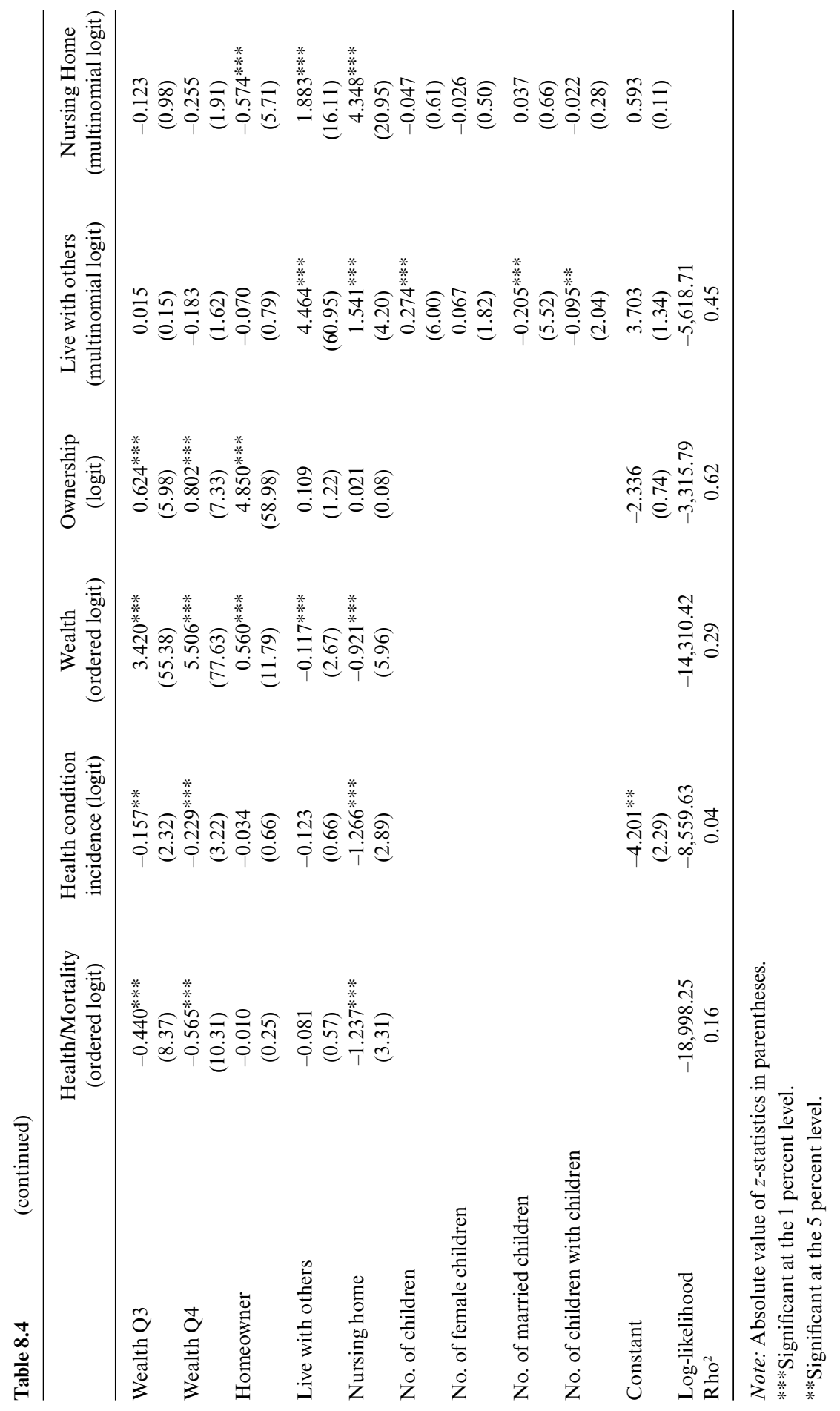


persistent over time in the sense that the reported health status in the previous wave is a strong predictor of mortality and current health status. In this health regression, we do not use lagged living arrangements directly. The reason for this is that living arrangements are driven by expectations of future health, leading to a serious endogeneity problem in this regression. Instead, we instrument living arrangements in this regression with detailed characteristics of children.

Many of the results of the health condition incidence regression are similar to the health status/mortality regression. The age coefficients are not individually significant, but a Wald test shows high joint significance $(W=$ $\left.83.59^{\mathrm{a}} \sim \chi_{[5]}^{2}\right)$. Being in the lowest wealth quartile increases the probability of suffering from a major health incident, but there is no significant difference between the three highest quartiles.

Respondents reporting a positive health status are more likely to be wealthier in the next interview, but the health conditions we included in our measure have no effect on wealth. Marital status is an important determinant of home ownership. Events like the death of the spouse and a major health incident lead to a high number of people selling their home. But variables like self-reported health status and wealth quartile also have important effects. The age spline has a significantly negative slope only for the respondents aged seventy-five to eighty years. For the others, factors like decreasing health seem to drive the further decrease of home ownership.

The results of the living arrangement regression show that living with others and living in nursing homes are in fact substitutes in the sense that the explanatory variables do have similar effects on the probabilities to choose one of these alternatives. Married couples tend to live alone until one spouse dies. The surviving spouse is very likely to move either into a child's home or into a nursing home shortly afterward. Health condition incidents also lead respondents to move in with somebody and-even more so-to move into a nursing home. Similarly, poor or fair health status leads to changes in this direction. Since most cohabitants are own children, their characteristics obviously play an important role in explaining cohabitation. Female children are more likely to live with their parents, whereas married children and those who have children themselves are less likely to do so.

\subsection{Simulating Trajectories}

According to equation (3), we can rebuild a full $289 \times 289$ transition matrix of survival and the six other state variables $\mathbf{y}_{t}$ for a given set of shift variables $\mathbf{x}_{t}$. Starting from a suitably chosen initial state, we are thus able to simulate predicted trajectories for our left-hand-side variables.

More specifically, we start these trajectories at age seventy and follow an elderly person through age ninety. A particularly interesting date of obser- 
vation is age eighty, approximately the conditional life expectancy given survival to age seventy. In the simulations, the estimated transition matrices are interpreted as being valid for two-year transitions in accordance to the biannual nature of the AHEAD data. This is important when interpreting the age variable.

The simulations are done in four steps:

1. Start at initial probabilities (typically 1 for one state, 0 for the others) and a set of shift variables $\mathbf{x}$ for $t=0$.

2. Calculate the $289 \times 289$ transition matrix as described above.

3. Predict probabilities for $t=1$.

4. Repeat steps $2-3$ until age ninety is reached.

We will perform several exercises. First, we predict whole system for different initial conditions, taking account of all (implicit) interactions. Second, in subsections 8.5.1 through 8.5.3, we look at various dimensions separately (like wealthy vs. poor, healthy vs. sick, etc.). For instance, how does survival, how do living arrangements, change with initial health, with initial wealth? Third, in subsection 8.5.4, we decompose the observed effects by leaving some of the left-hand-side variables at their starting values. This amounts to setting some off-diagonal elements in the transition matrix to zero and therefore annihilates interaction effects. Note that we painfully avoid any notion of causality - these exercises should be interpreted as simulations of persons under different circumstances and initial conditions. Finally, in subsection 8.5.5, we simulate shocks such as the onset of a health condition and look at the resulting response pattern. This last exercise is well known in the macroeconomics literature as "response analysis."

To warm up to our methodology, we start with figure 8.2, which shows the trajectories of two very different people. The top figure shows a poor single person in bad health, while the bottom figure depicts a rich married person in good health. Good health is defined by a self-reported health status of excellent or very good, bad health by a self-reported health status of poor or fair. The rich person is in the highest wealth quartile, while the poor person is in the lowest one. All other characteristics are identical. Both persons are male, have no children, have no previous health conditions, and live independently in an owner-occupied home.

The figure presents the evolution of our seven state variables, each represented by a line that starts at an initial probability and then moves from that initial probability as the two people age. The first five state variables start at identical initial values for both persons. The solid line depicts the survival probability, starting with 1 and declining with age. The smalldotted line shows the probability of a health condition, starting with zero and increasing with age. The line with triangles is the probability of home ownership. It starts at 1 and declines with age. The line with circles repre- 


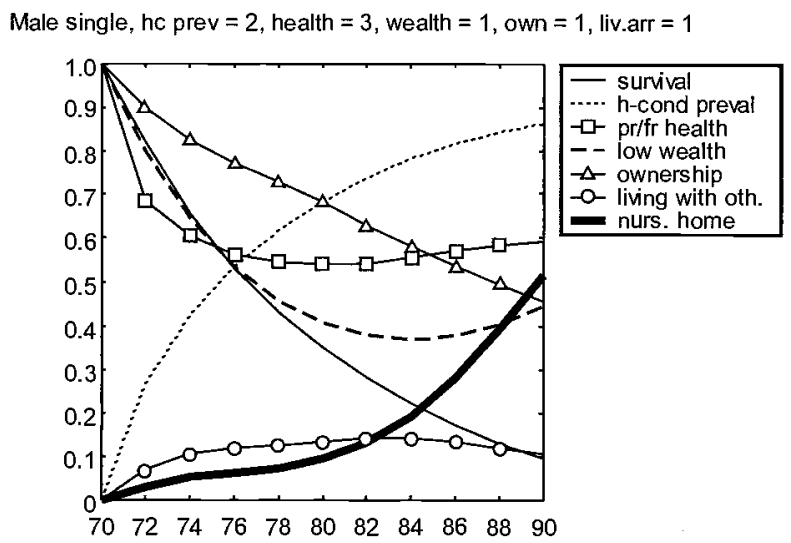

Male married, hc prev $=2$, health $=1$, wealth $=4$, own $=1$, liv.arr $=1$

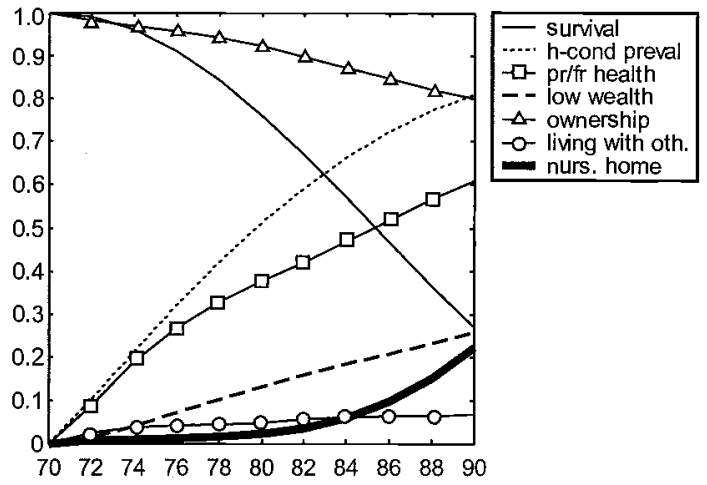

Fig. 8.2 Trajectories of two very different people

sents the probability of living with others, the thickest solid line living in a nursing home. Both start at zero and increase with age. Finally, two state variables start at different values, namely wealth, represented by a largedotted line, and self-reported health, depicted by a line with squares.

Quite clearly, survival at age eighty is much higher (about 40 percent) for the healthy, rich, and married person. The probability of ending up in poverty is, as expected, also much lower. Note that the trajectories eventually converge. In the long run, we are all dead. Mathematically speaking, the outcome of the Markov process will eventually be independent of the initial state and converge on a state solely defined by the transition matrix. For a given age, this matrix depends on "shift" variables such as sex, the number of children, and so on - that is, the $\mathbf{x}_{t}$ in equation (2).

It is worthwhile to look at various details in figure 8.2 to understand which mechanisms are picked up by our estimated transition probabilities. 
For instance, it is noticeable that the probability of reaching the lowest quartile in the wealth distribution increases again for the poorer person past age eighty-four, which probably reflects nursing home costs - the poorer single person of worse health has a much higher likelihood of living in a nursing home than the richer married person of good health.

We now analyze the state variables separately and investigate their interaction with other state variables. Subsection 8.5.1 looks at survival and health, subsection 8.5.2 at wealth and home ownership, and subsection 8.5.3 at living arrangements of the elderly.

\subsubsection{Survival and Health}

We begin with survival and relate it to initial wealth and initial health. Figure 8.3 shows the probability of survival as a function of two initial health characteristics, self-reported health ("would you rate your health as fair/poor vs. excellent/very good") and the existence of at least one previous serious health condition ("has a doctor ever told you . .."), where serious conditions include heart problems, stroke, and cancer. The survival curves remain essentially parallel whether such a condition exists or not, while the effect of the self-rated health assessment is strong, maybe measuring other conditions, such as arthritis or diabetes, that are making life difficult without being immediately life threatening.

Figure 8.4 shows survival stratified by initial wealth. Survival at age eighty, given survival until age seventy, is about 15 percent higher in the highest wealth quartile as compared to the lowest wealth quartile. The bot-

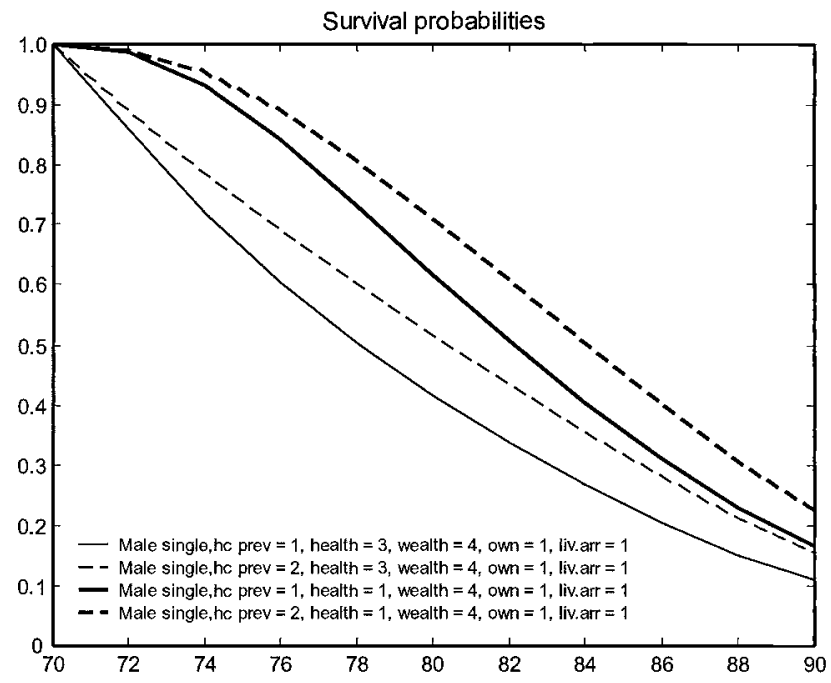

Fig. 8.3 Survival by health status 

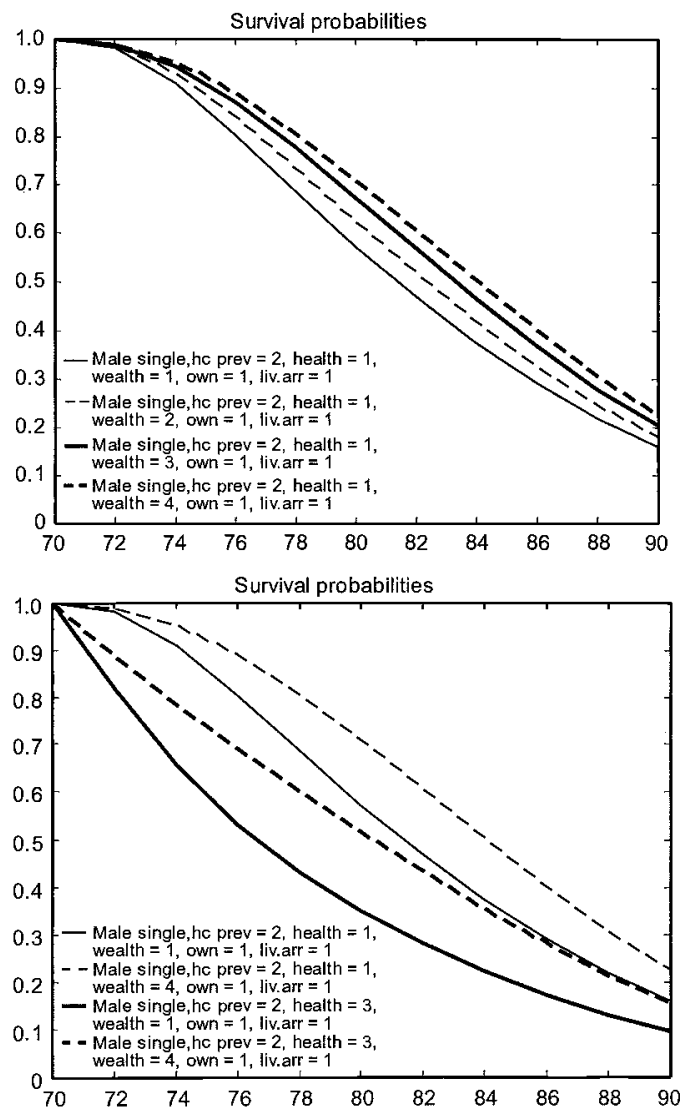

Fig. 8.4 Survival by wealth quartile and its interaction with health

tom part of the figure shows the interaction of wealth and health in determining survival, and the relative magnitudes of the effects: survival, while clearly dependent on initial wealth, is influenced much more strongly by initial health.

Similar to survival, health is quite clearly influenced by initial economic status. Figure 8.5 shows the evolution of two dimensions of health over time, each stratified by whether the person is initially in the lowest or the highest wealth quartile. The top part of the figure depicts self-reported health, the bottom part the prevalence of a serious health condition. Being wealthy decreases the likelihood of feeling in bad health by about 12 percentage points at age seventy-five relative to being in the lowest wealth quartile. This wealth effect is much smaller for an actual occurrence of a serious health condition. 

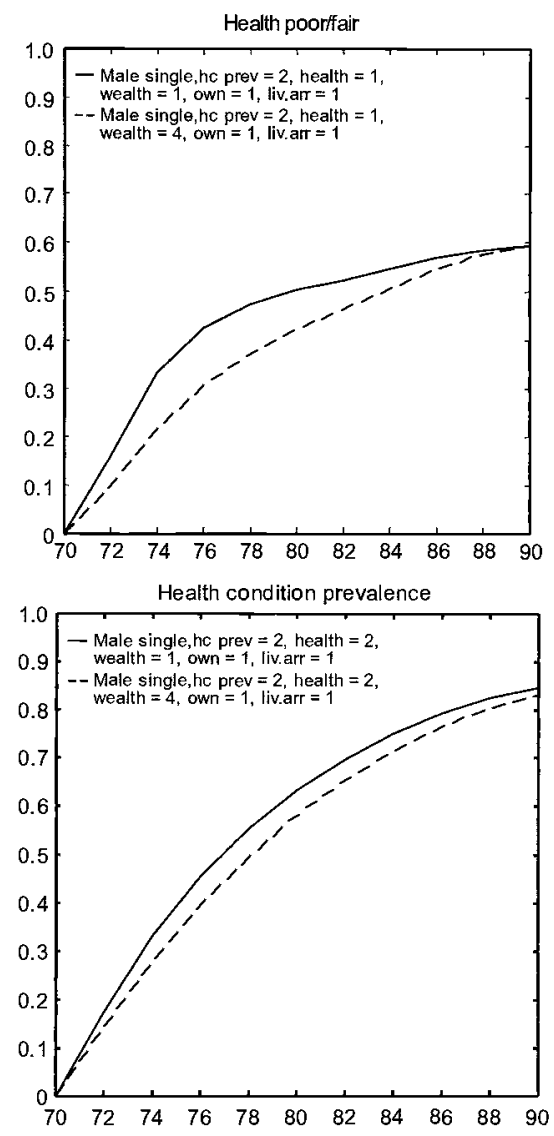

Fig. 8.5 Health by lowest and highest wealth quartile

\subsubsection{Wealth and Home Ownership}

We now turn to wealth and home ownership, starting with the latter. Home ownership declines slowly but steadily as people age (see figure 8.6). The decline in home ownership follows from the tendency of the system to converge. Hence, its speed is the interesting observation, since this relates to our regression estimates of section 8.4. Quite clearly, home ownership declines much less for married elderly people than for single ones. It also declines faster for the poor (more precisely, those with total wealth in the lowest quartile) than for the rich (highest wealth quartile). We will investigate this decline more closely in section 8.6.

The tendency of the system to converge is also clearly visible in figure 8.7, which depicts the evolution of wealth. The top part of this figure shows a poor person (lowest wealth quartile) and the probability of staying in this 


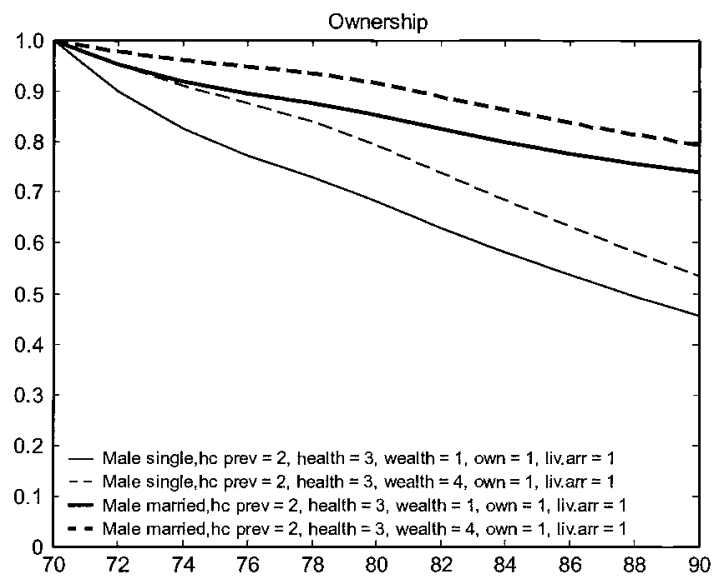

Fig. 8.6 Home ownership by wealth and marital status
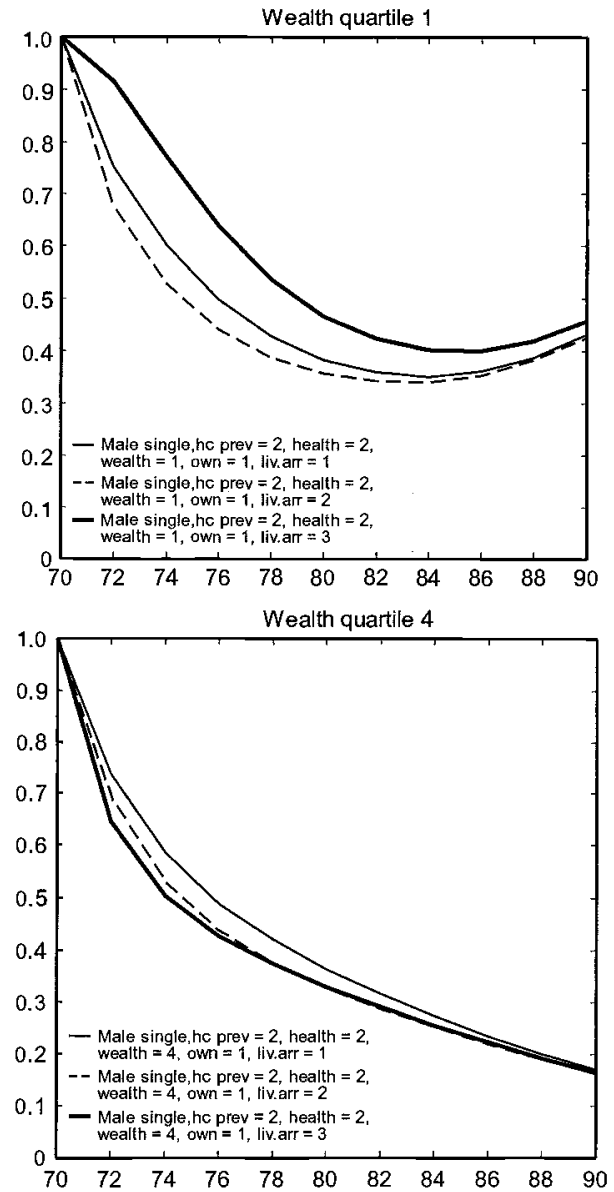

Fig. 8.7 Wealth by living arrangement 
quartile. This probability declines, but increases again, most likely due to nursing home costs. Figure 8.7 stratifies this decline by initial living arrangement. Staying in the poor quartile is most likely when an elderly person lives in a nursing home, and least likely when this person lives with others. ${ }^{2}$ The bottom part of figure 8.7 shows the reversed patterns as it looks at the probability of staying in the highest wealth quartile. For the initially wealthy, living with others decreases the expected future wealth relative to living alone. This is consistent with the notion that cohabitation implies intrafamily transfers to the needy.

\subsubsection{Living Arrangements}

We now turn to the main topic of this paper-namely, living arrangements. We distinguish three living arrangements: living alone (or as a couple), living with others (mainly with adult children), and living in a nursing home. Figure 8.8 depicts the probability of the first two living arrangements and shows the effect of additional children, in this case three daughters. Figure 8.9 adds the probability of living in a nursing home. The figures compare a single male, who has no previous health conditions, who rates his health as fair or poor, who is in the lowest wealth quartile, and who has one son with a similar male who has, in addition, three daughters.

Having daughters substantially decreases the probability of being alone at age eighty (by about 20 percent) and living in a nursing home (by about 10 percent) in favor of living with others - that is, being taken in by one of the daughters (by almost 30 percent). Interesting is the gender-specific effect of additional children. As shown in many other papers, daughters reduce the likelihood of living in a nursing home substantially more than sons (see figure 8.9).

\subsubsection{Decomposing the Effects: Keep Some Dimensions Fixed}

The next experiment separates direct and indirect effects. In the previous simulations, all left-hand-side variables in equation (1) were predicted using the full transition matrix. Now we hold certain dimensions constant. As an example, we show the evolution of the survival probabilities (figure 8.10 ) and the probability of being in the highest wealth quartile (figure 8.11). The figures show how the interaction effects in the full model dampen the effects that would be predicted without the interactions.

We begin with the survival probabilities in figure 8.10. The solid line shows the trajectory using the full model with all interactions. In all other lines, the occurrence of a serious health condition is fixed at "no occurrence." This shifts, as expected, the survival probabilities up (light-dotted line). If we also assume that self-reported health stays fixed at "excellent or

2. Remember that this finding should not be interpreted in a causal fashion: we only know that the two processes (wealth decumulation and where to live) are correlated, not which process causes which other process to change. 

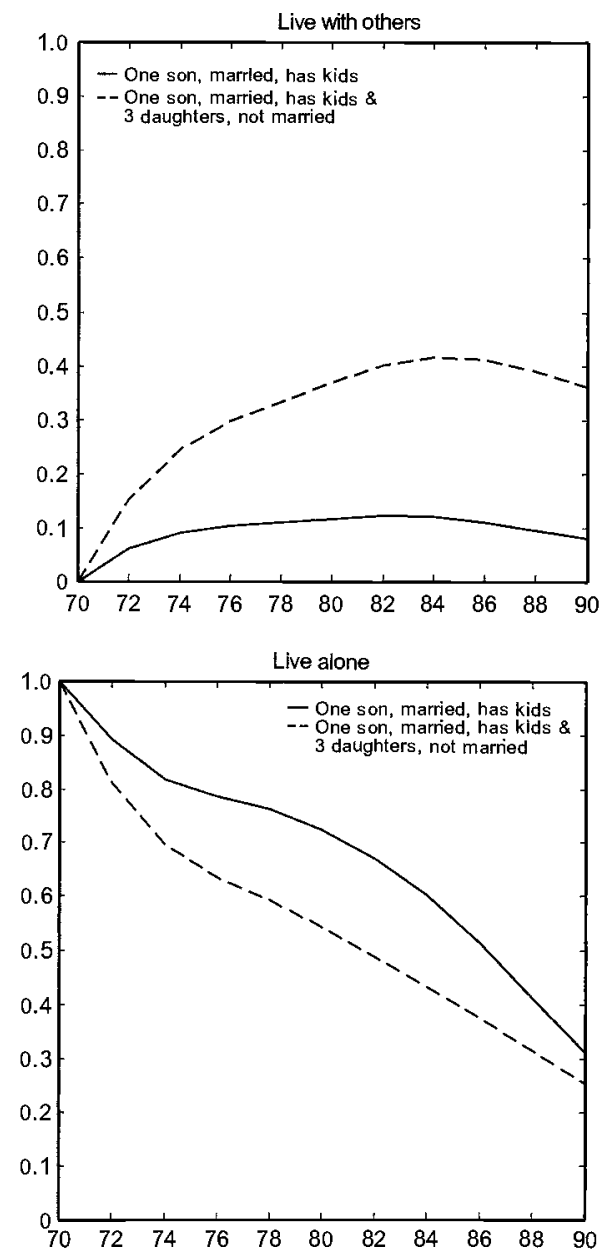

Fig. 8.8 Probability of living alone or with another person in the community

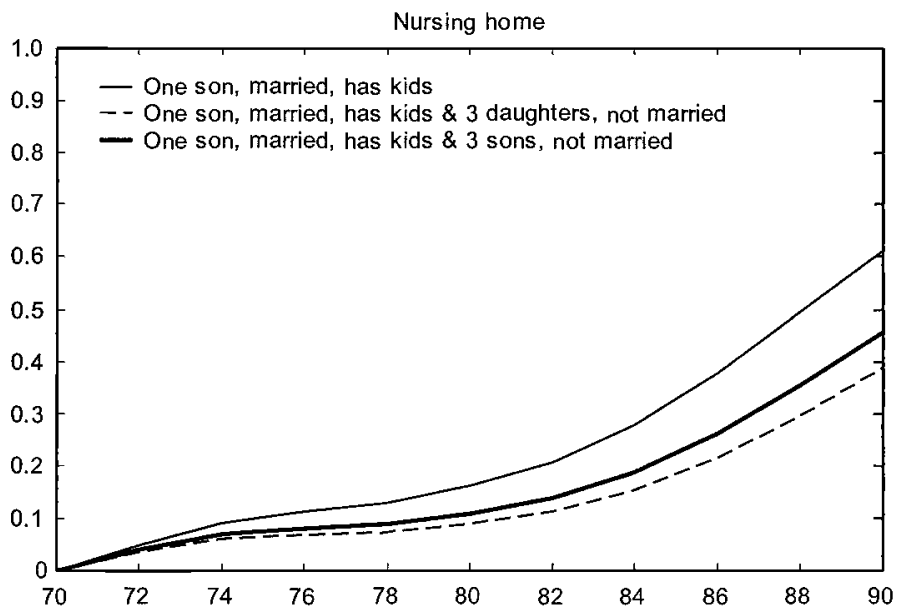

Fig. 8.9 Probability of living in a nursing home 


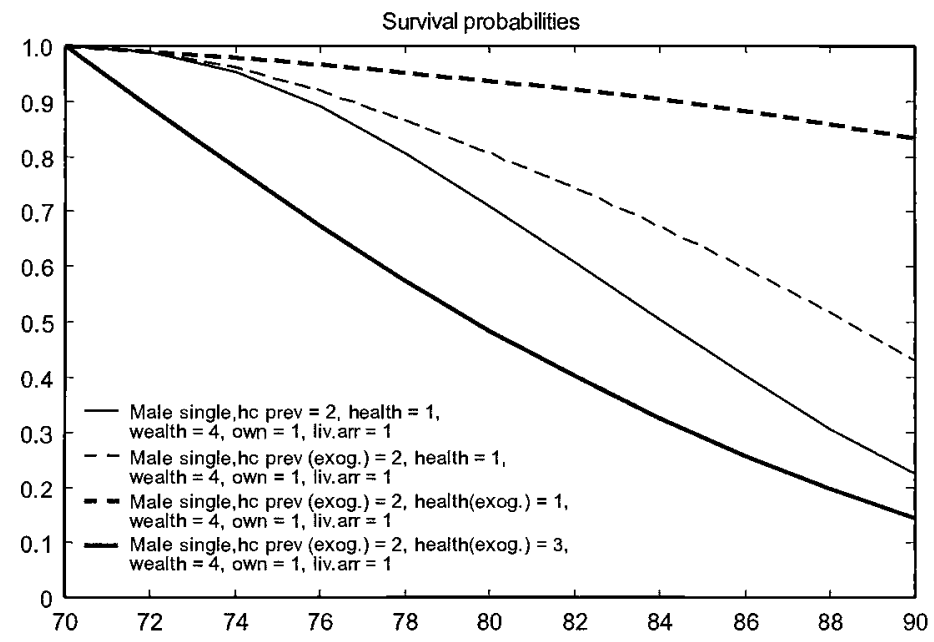

Fig. 8.10 Decomposing survival probabilities by health effects

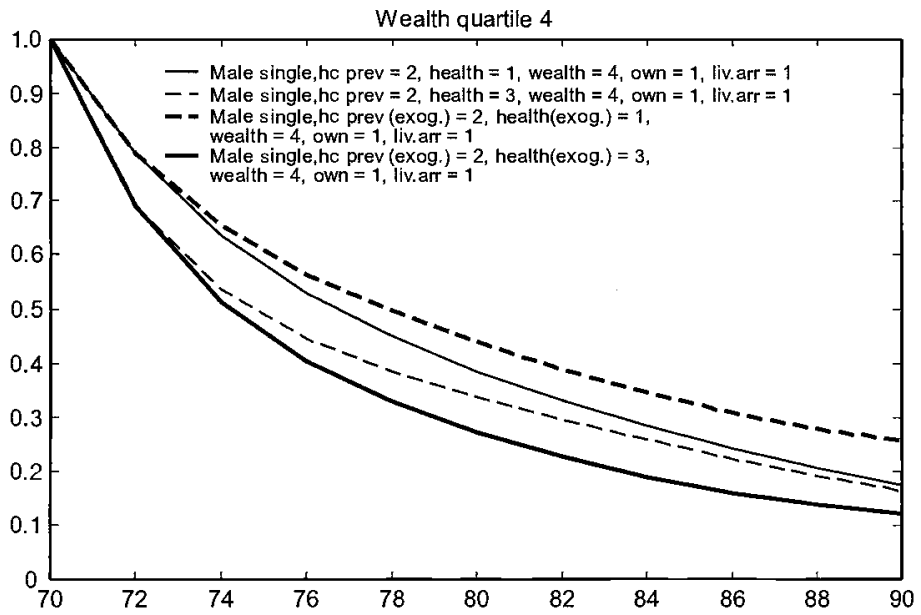

Fig. 8.11 Decomposing the probability of being wealthy

very good," survival rates stay very high and decline only slowly (darkdotted line). Fixing self-reported health at a "poor or fair" level, of course, creates the opposite effect (thick solid line).

Figure 8.11 performs a similar exercise with the probability of being in the highest wealth quartile. The solid and the light-dotted lines show initial trajectories using the full model with all interactions. The solid line starts with a healthy individual (self-rated health "excellent or very good"), the light-dotted one with an unhealthy elderly individual (self-rated health "poor or fair"). Note that the two lines eventually merge - there is no long- 
run effect of health on wealth, although at age seventy-five the probability of being in the highest wealth quartile is substantially higher for the initially healthy individual.

If we now keep the initial health status fixed (thick-dotted and thick solid lines), the trajectories stay apart. The probability of staying in the highest wealth quartile is about 15 percent higher for the elderly individual, who stays healthy through age ninety.

\subsubsection{Dose and Response Analysis}

Finally, we look at the behavior of the multidimensional system in response to shocks. Figure 8.12 depicts the survival probability after a health shock ("doctor told person about one of the following three conditions: heart problem, onset of cancer, or stroke"). We compare this thick solid trajectory to the one generated by the full model (with all interactions, solid line) and to two variants in which the health condition is kept fixed, as we did in the previous subsection. We fix it at "no conditions" (lightdotted line) and at "some conditions exist at the age of seventy, but no further incidents occur" (thick-dotted line).

Figure 8.12 shows that the survival probabilities in the aftermath of a health shock follow pretty much the long run paths. There are no overshooting or other complex dynamic effects. This is quite different for the self-reported health status; see figure 8.13. We apply the same shock but focus on self-reported health as outcome variable. The thick solid line depicts the typical "overshooting" after a shock vis-à-vis the trajectory where this condition has happened in the past. After a while, the health status perception variable returns approximately to the long-run path.

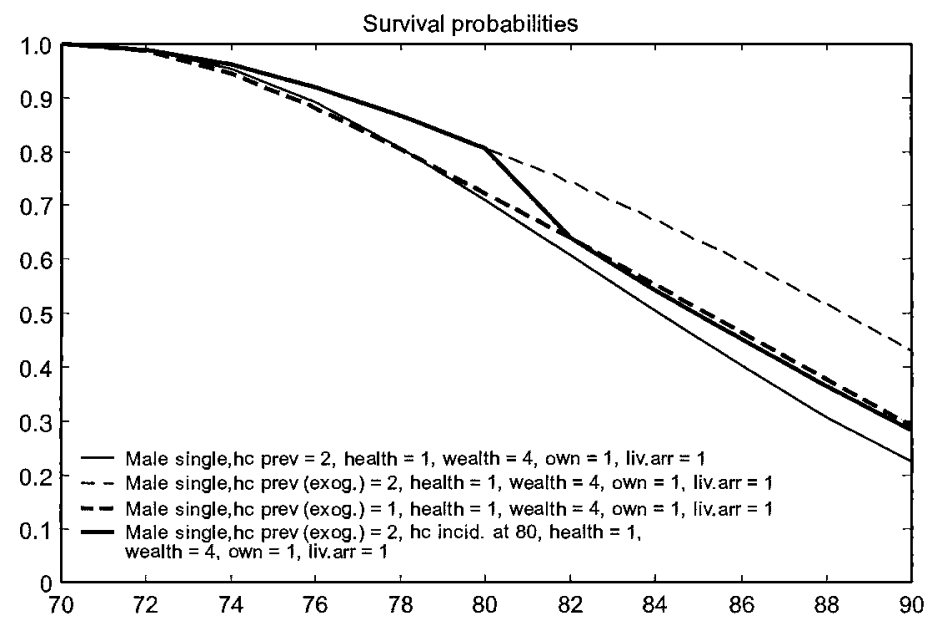

Fig. 8.12 Survival probabilities in response to a health shock 


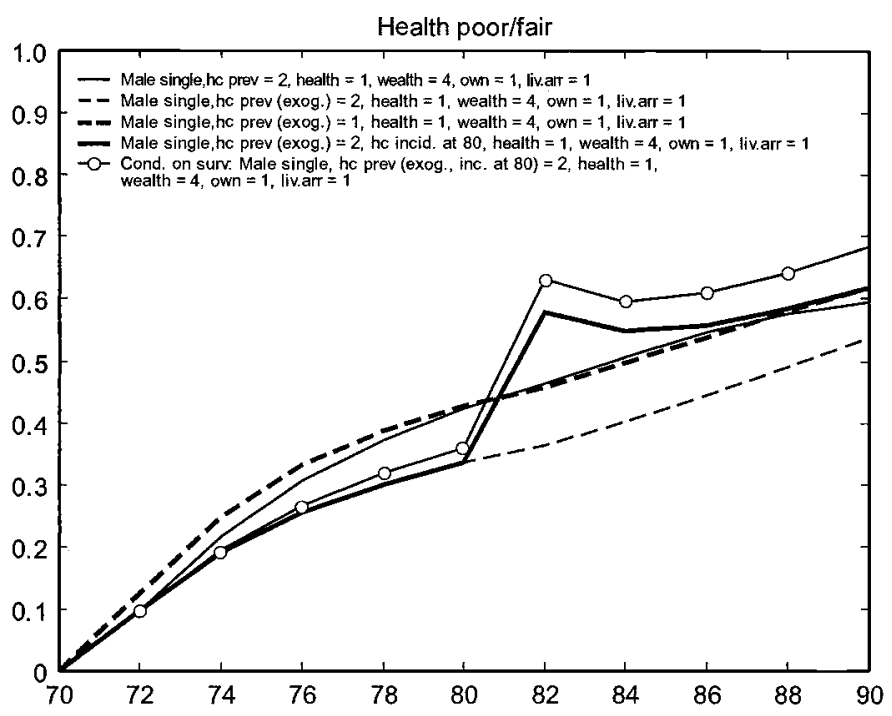

Fig. 8.13 Self-rated health in response to a health shock

Part of this effect, however, is a selection effect due to differential mortality. If we also keep the survival variable fixed at probability one (see the line with circles in figure 8.13), subjective health stays worse for a long time past the occurrence of the shock for those who actually survive.

\subsection{Do the Elderly Downsize Housing?}

In the preceding section, we found that home ownership decreases with age. We noted that the Markov process has the built-in property of convergence; hence, declining home ownership is, to some extent, an artifact built into the model. We did, however, detect some significant differences in the speed of decline depending on the initial characteristics of the elderly person. This suggests that there are elderly in our sample who systematically decumulate housing. This section looks closer at the issue of home ownership. We note that ownership is somewhat different from housing equity, which can be influenced by mortgage repayment, housing price changes, or neglect of maintenance. Venti and Wise $(1990,2001)$ found that in general the elderly to not reduce home equity except at the death of a spouse.

Table 8.5 shows cross-section housing and living arrangements by age bands. About 82 percent of those seventy to seventy-four years old were owners, and most of them lived "alone," either with a spouse only or singly. The table shows a slow but accelerating decline in ownership with age and a corresponding increase in renting, although until age eighty-five or over 
Table 8.5

Home ownership and living arrangements, percent distribution

\begin{tabular}{lrrrr}
\hline & $70-74$ & $75-79$ & $80-84$ & $85+$ \\
\hline Own home & 81.6 & 77.2 & 70.7 & 57.6 \\
Alone & 66.4 & 64.0 & 57.3 & 43.1 \\
With others & 14.7 & 12.1 & 11.5 & 9.0 \\
$\quad$ Nursing home & 0.5 & 1.1 & 1.9 & 5.5 \\
Rent home & 14.0 & 16.3 & 18.1 & 22.2 \\
$\quad$ Alone & 11.1 & 13.7 & 15.7 & 18.7 \\
With others & 2.9 & 2.6 & 2.4 & 3.5 \\
Neither own nor rent & 4.3 & 6.0 & 9.5 & 13.1 \\
Not own, nursing home & 0.2 & 0.6 & 1.8 & 7.0 \\
All & 100.0 & 100.0 & 100.0 & 100.0 \\
$N$ & 4,099 & 7,157 & 5,427 & 4,535 \\
\hline
\end{tabular}

Source: AHEAD pooled cross-sections (four waves).

Table 8.6 Home ownership and living arrangements, percent distribution: Married

\begin{tabular}{lrrrr}
\hline & $70-74$ & $75-79$ & $80-84$ & $85+$ \\
\hline Own home & 90.4 & 88.6 & 85.5 & 77.1 \\
$\quad$ Alone & 76.7 & 77.8 & 75.3 & 67.1 \\
With others & 13.3 & 10.2 & 8.8 & 5.9 \\
Nursing home & 0.4 & 0.6 & 1.4 & 4.1 \\
Rent home & 7.7 & 8.6 & 10.0 & 14.0 \\
$\quad$ Alone & 6.5 & 7.2 & 9.2 & 13.2 \\
$\quad$ With others & 1.2 & 1.4 & 0.8 & 0.8 \\
Neither own nor rent & 1.9 & 2.5 & 4.2 & 5.8 \\
Not own, nursing home & 0.0 & 0.2 & 0.4 & 3.0 \\
All & 100.0 & 100.0 & 100.0 & 100.0 \\
$N$ & 2,555 & 3,733 & 2,238 & 1,232 \\
\hline
\end{tabular}

Source: AHEAD pooled cross-sections (four waves).

the increase is small. Most notable in the table is the increase in "other," which includes neither renting nor owning (mostly living with children in their house) and living in a nursing home, especially at age eighty-five or over.

Because of differential mortality we would expect a greater decline in owning in panel than we see in cross section, although cohort differences could obscure this decline.

Table 8.6 has cross-section housing and living arrangements for married persons. The patterns are similar to the patterns in table 8.5, but there is a much slower reduction in ownership with age. By age eighty-five or over the ownership rate is 13 percentage points lower than at seventy to seventyfour, whereas in table 8.5 it is 24 percentage points lower. In the oldest group about 7 percent live in a nursing home. 
Table 8.7

Home ownership and living arrangements, percent distribution: Singles

\begin{tabular}{lrrrr}
\hline & $70-74$ & $75-79$ & $80-84$ & $85+$ \\
\hline Own home & 66.8 & 64.7 & 60.1 & 50.3 \\
$\quad$ Alone & 49.2 & 48.9 & 44.5 & 34.1 \\
With others & 17.0 & 14.2 & 13.4 & 10.2 \\
$\quad$ Nursing home & 0.6 & 1.6 & 2.2 & 6.0 \\
Rent home & 24.6 & 24.5 & 23.8 & 25.3 \\
$\quad$ Alone & 18.8 & 20.7 & 20.3 & 20.8 \\
With others & 5.8 & 3.8 & 3.5 & 4.5 \\
Neither own nor rent & 8.2 & 9.8 & 13.3 & 15.9 \\
Not own, nursing home & 0.5 & 1.0 & 2.8 & 8.5 \\
All & 100.0 & 100.0 & 100.0 & 100.0 \\
$N$ & 1,544 & 3,420 & 3,178 & 3,298 \\
\hline
\end{tabular}

Source: AHEAD pooled cross-sections (four waves).

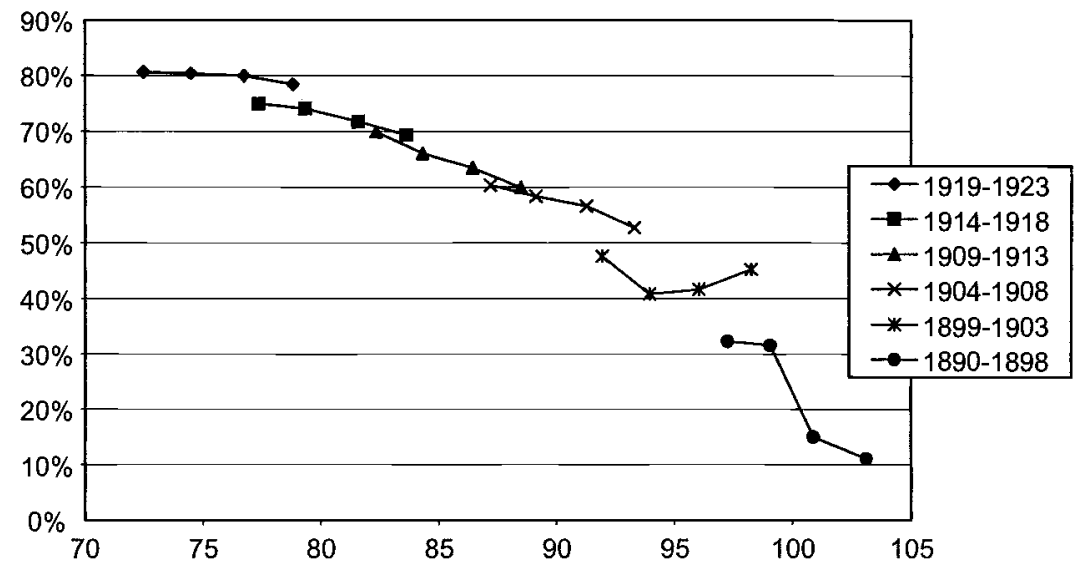

Fig. 8.14 Home ownership rates in six cohorts: Percentages

Source: AHEAD pooled cross sections (four waves).

Table 8.7 has similar results for singles. The levels of ownership are lower and decline at a greater rate with age. By age eighty-five or over 14.5 percent live in nursing homes and 15.9 percent neither own nor rent.

Figure 8.14 has the average ownership rates by cohort. For example, approximately 75 percent of the cohort of birth years 1919-23 owned a house in wave 1 of AHEAD (when the cohort was approximately seventy-seven), and the ownership rate of the cohort declined to 69 percent when the cohort was about eighty-four in 2000 . The figure shows that cohort differences are relatively minor: holding age constant, cohort ownership rates are approximately the same. ${ }^{3}$ The cohort comparisons include differential

3. But the sample sizes are small in some cases. 
Home ownership transition rates: Survivors only (\%)

\begin{tabular}{|c|c|c|c|c|c|}
\hline \multirow[b]{2}{*}{ Marital transition } & \multirow[b]{2}{*}{ Age } & \multirow[b]{2}{*}{ Lagged ownership } & \multirow[b]{2}{*}{ Number } & \multicolumn{2}{|c|}{ Ownership status } \\
\hline & & & & Own & Not own \\
\hline \multirow[t]{8}{*}{ Married to married } & \multirow[t]{2}{*}{$70-74$} & Own & 2,013 & 98.3 & 1.7 \\
\hline & & Not own & 179 & 9.5 & 90.5 \\
\hline & \multirow{2}{*}{$75-79$} & Own & 2,142 & 97.0 & 3.0 \\
\hline & & Not own & 259 & 11.2 & 88.8 \\
\hline & \multirow[t]{2}{*}{$80-84$} & Own & 1,068 & 94.4 & 5.6 \\
\hline & & Not own & 160 & 12.5 & 87.5 \\
\hline & \multirow[t]{2}{*}{$85+$} & Own & 419 & 93.8 & 6.2 \\
\hline & & Not own & 114 & 10.5 & 89.5 \\
\hline \multirow[t]{8}{*}{ Single to single } & \multirow[t]{2}{*}{$70-74$} & Own & 929 & 94.6 & 5.4 \\
\hline & & Not own & 449 & 8.9 & 91.1 \\
\hline & \multirow[t]{2}{*}{$75-79$} & Own & 1,568 & 91.8 & 8.2 \\
\hline & & Not own & 858 & 8.2 & 91.8 \\
\hline & \multirow[t]{2}{*}{$80-84$} & Own & 1,201 & 90.0 & 10.0 \\
\hline & & Not own & 762 & 4.2 & 95.8 \\
\hline & \multirow[t]{2}{*}{$85+$} & Own & 855 & 89.0 & 11.0 \\
\hline & & Not own & 817 & 5.4 & 94.6 \\
\hline \multirow[t]{8}{*}{ Married to single } & \multirow[t]{2}{*}{$70-74$} & Own & 146 & 93.2 & 6.8 \\
\hline & & Not own & 34 & 8.8 & 91.2 \\
\hline & \multirow[t]{2}{*}{$75-79$} & Own & 223 & 86.1 & 13.9 \\
\hline & & Not own & 55 & 12.7 & 87.3 \\
\hline & \multirow[t]{2}{*}{$80-84$} & Own & 155 & 85.2 & 14.8 \\
\hline & & Not own & 44 & 0.0 & 100.0 \\
\hline & \multirow[t]{2}{*}{$85+$} & Own & 86 & 79.1 & 20.9 \\
\hline & & Not own & 28 & 7.1 & 92.9 \\
\hline
\end{tabular}

Source: AHEAD pooled cross-sections (four waves).

mortality, the tendency for renters to die sooner than owners. Differential mortality causes average ownership to increase even if there is no reduction in ownership in the panel.

Table 8.8 shows panel transitions among survivors. Among marrieds in the youngest age group, there were very low rates of transition out of ownership, and some transitions into ownership. But the predominant flow is out because of high rates of ownership. The transition rate out of ownership increases with age.

From the flows the steady-state rate of ownership (the ownership rate were the transition rates into and out of ownership to remain constant for the indefinite future) is given by

$$
\frac{T}{1+T}
$$

where $T=\left(1-P_{00}\right) /\left(1-P_{11}\right), P_{00}$ is the transition probability from not owning to not owning, and $P_{11}$ is the transition probability from owning to own- 
ing. Among those married in both waves $t$ and $t+1$ and in the age band seventy to seventy-four the steady-state rate of ownership is 84.8 percent and the actual average is 91.8 percent. Thus, there is a trend out of ownership among marrieds, but the trend is slow. Among marrieds aged eightyfive or over, the steady-state rate is 62.9 percent and the average is 78.6 percent, also showing a downward trend in ownership.

Among those who were single in two adjacent waves the transition rate out of ownership increases with age. The steady-state rates decline from 62.2 percent in the age band seventy to seventy-four to 32.9 percent in the age band eighty-five or over.

Widowing is associated with considerably higher rates of transition out of ownership: for example, among those aged seventy to seventy-four who were widowed between adjacent waves the transition rate out of ownership was 6.8 percent, compared with just 1.7 percent among surviving couples. This rate increases sharply with age.

We ask whether the panel transitions can explain the cross-section patterns of ownership that are in table 8.5. Figure 8.14 indicated that cohort differences are not important, but we must still address differential mortality. The average risk (holding age constant) of a renter's dying compared with an owner's dying is about 1.39: said differently, the age-adjusted mortality rate of renters is about 39 percent higher than the mortality rate of owners. In that renters die more frequently than owners, the average rate of ownership by a cohort will increase over time even if there are no transitions into or out of ownership in panel among survivors. However, the rate of ownership is high so that differential mortality will not increase the average ownership rate substantially as a cohort ages. Under the assumption that owners and renters have the same mortality risk, the average over all groups, the home ownership rate would decline by about 0.4 percent per year more than the observed cohort rate. The difference is shown in figure 8.15: it shows the cross-section ownership rates averaged over four waves of AHEAD data, the rates predicted from the panel ownership transitions reported in table 8.8 (panel), and the rates predicted both from the panel and from differential mortality (panel accounting for differential mortality).

The cumulative effects of differential mortality can be seen by comparing the two panel lines: after about fifteen years the simulation that accounts for differential mortality is about 5 percentage points above the simulation that does not. The cross section is very closely matched by the simulation that accounts for differential mortality showing that cohort effects are not very important and that the transition rates over the period of our sample (mid- to late 1990s) have been stable for a considerable time.

The difference between the time paths of ownership by singles and by couples and the effects of widowing on ownership are shown in figure 8.16. The top curve, for couples, and the bottom curve, for singles, are derived 


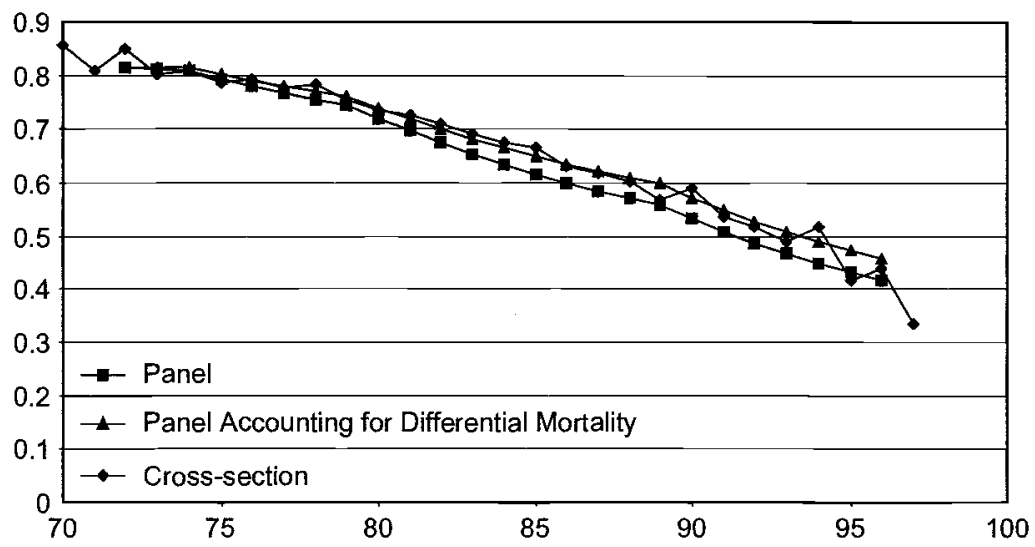

Fig. 8.15 Ownership rates: Cross section and simulation

Source: Own computations based on AHEAD.

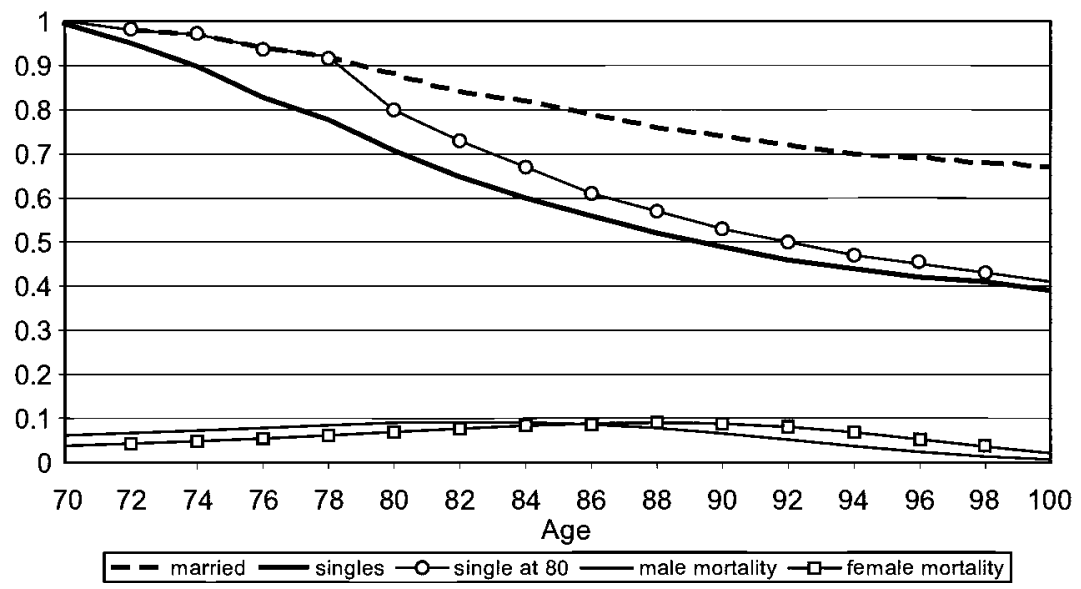

Fig. 8.16 Projected ownership rates

Source: Own computations based on AHEAD.

from the estimated transition rates in ownership in table 8.4 beginning with an ownership rate of 100 percent at age seventy. The curves are conditional on survival and so have the interpretation of anticipated lifetime probabilities of owning. Thus, if both members of a couple survive to ninety, the probability of owning will decline to about 75 percent. Among singles who are owners at age seventy the rate of decline is considerably greater, and the probability of owning at age ninety less than 50 percent. The middle curve shows predicted rates of ownership of couples who are owners at age seventy, but where one spouse dies between seventy-eight and seventy-nine. 


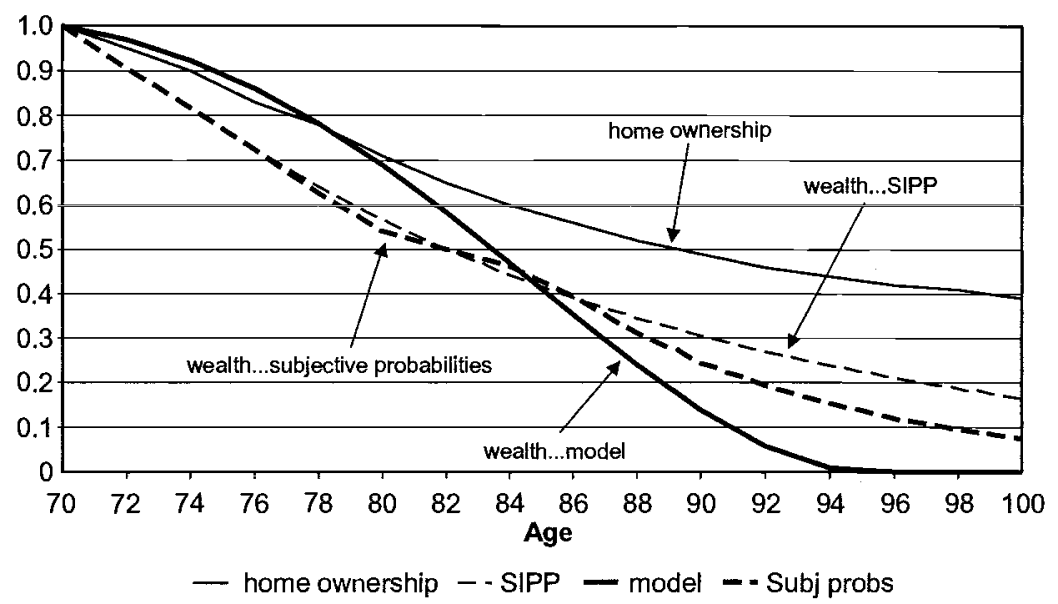

Fig. 8.17 Home ownership and wealth

Source: Own computations based on AHEAD.

During the one-year transition period to widowhood the probability of owning declines sharply, as shown in table 8.4, and then the probability follows the path of singles but at a higher level.

The two curves at the bottom of figure 8.16 show the probability of males and of females dying at each age conditional on reaching age seventy. The most likely age for males to die is eighty-two, and it is eighty-eight for females. The figure suggests that 50-60 percent of couples who are owners at age seventy will be owners at the death of the surviving spouse, and that a somewhat lower fraction of singles will be owners. These percentages are not much different from the estimates of Sheiner and Weil (1992), who estimated that among couples who were owners at age sixty-five, just 41 percent of the last survivor would die still owning.

The life-cycle model (LCM) predicts that wealth will be decumulated as people age, and in figure 8.17 we compare the wealth paths predicted in three different ways with the rate of ownership among singles. The objective of the comparison is to find whether the path of ownership as an indicator of housing wealth is broadly consistent with wealth paths as predicted by the LCM. The first wealth forecast (labeled wealth . . SIPP) uses observed wealth change in the 1984-85 Survey of Income and Program Participation (SIPP) panel. The second (labeled wealth ... subjective probabilities) is based on the subjective probability of bequests as elicited in the HRS. Hurd and Smith (2002) compared them with actual bequeathable wealth to estimate annual rates of anticipated dissaving, which we use to construct the curve. The third (labeled wealth . . model) uses an LCM estimated over the 1969-79 Retirement History Survey to predict the path 
of bequeathable wealth (Hurd 1989). ${ }^{4}$ The rates of decumulation of bequeathable wealth are broadly consistent with each other. They predict that a single person who survives into his or her nineties will have consumed three-fourths or more of bequeathable wealth.

The path of home ownership initially follows the path of bequeathable wealth, but after about ten years it is higher than all of them. The lower rate of decline probably reflects a number of ways in which housing wealth is treated differently from nonhousing wealth. There are substantial transaction costs in moving from home ownership to renting, so that there will be a tendency to retain housing beyond what would be optimal were adjustment costless. People have a sentimental attachment to a particular house, which increases the transaction costs. There is risk associated with renting, such as inflation in rental costs, whereas, except for property tax and maintenance, owned housing is a way of purchasing a stream of real consumption.

We can find whether the increase with age in the rate transitions out of owning is a pure age effect or is associated with characteristics such as health or economic circumstances. Our method is to estimate the probability of owning in wave $t+1$ as a function of characteristics and economic circumstances as well as ownership status in wave $t$. Using four waves of AHEAD, we have three transitions. Table 8.9 shows the ratio of the probability of owning to not owning (the risk of owning) of someone with one of the characteristics displayed in the first column divided by the risk of owning of someone in the reference group. These results are estimated by multivariate logit over the three transitions. Thus, someone who is married has a risk of owning in wave $t+1$ that is 124 percent higher than the risk of someone who is not married, and the difference is significant at less than the 0.001 level.

The covariates with substantial explanatory power and statistical significance are the death of a spouse, which reduces the likelihood of owning in the next wave; the incidence of a health event; baseline health of fair or poor; and measures of wealth, as well as ownership itself. Of note is that age per se is not associated with an accelerating transition out of home ownership. This implies that the increased transition rates by age band that are in table 8.8 are due to worsening health and possibly reductions in wealth that occur with age.

4. We would like to use the AHEAD wealth data for this comparison, but two problems prevent its use: stock ownership was apparently underreported by about 10 percentage points in the 1993 wave, leading to a very large increase in measured wealth between 1993 and 1995 (Rohwedder, Haider, and Hurd 2004). There is no obvious way to correct for this data error. The 1995 wave of AHEAD was followed by the stock market boom, leading to wealth increases that were likely unanticipated and do not reflect planned life-cycle wealth accumulation. 
Relative risk for home ownership, logit estimates

\begin{tabular}{lcc}
\hline & Risk & $p$-value \\
\hline Female & 0.90 & 0.169 \\
Married & 2.24 & 0.000 \\
Spouse died & 0.34 & 0.000 \\
Age splines & 1.00 & 0.994 \\
70 & 0.90 & 0.090 \\
75 & 1.07 & 0.174 \\
80 & 1.04 & 0.526 \\
85 & 0.93 & 0.377 \\
90 & 1.05 & 0.484 \\
Health condition & 0.68 & 0.000 \\
Health incident & 0.99 & 0.936 \\
Health good & 0.79 & 0.006 \\
Health fair/poor & 0.60 & 0.000 \\
Housing wealth quartile lowest & & \\
Quartile 2 and 3 & 1.19 & 0.063 \\
$\quad$ Highest & 0.87 & 0.094 \\
Nonhousing wealth quartile lowest & & \\
Quartile 2 and 3 & 1.32 & 0.002 \\
$\quad$ Highest & 101.67 & 0.000 \\
Home owner & 1.09 & 0.359 \\
Live with others & 1.13 & 0.607 \\
Nursing home & &
\end{tabular}

Source: Own computations based on AHEAD.

We have included two wealth measures: housing wealth and nonhousing wealth. For each we define three categories: the lowest wealth quartile, the second and third quartiles, and the highest quartile. Both types of wealth are associated with higher levels of ownership. That is, those with more housing wealth and those with more nonhousing wealth tend to retain ownership. We had anticipated that high housing wealth combined with low nonhousing wealth would be associated with an elevated probability of selling the home, but the four interactions were neither economically nor statistically significant.

In summary, we find that home ownership is reduced with age but that the rate of reduction is less than the rate of reduction of nonhousing wealth. The lower rate of decline is likely due to a mixture of causes: housing may be held for a precautionary motive, as in Skinner (1996); it may be held until health makes ownership infeasible, whereas health should not affect the ability to hold financial wealth; and in that its sale is often associated with widowing, as in Venti and Wise (2001), it may be used to cover costs associated with widowing.

Some of these explanations are consistent with an LCM extended to include precautionary saving: poor health or a health event are predictors of reduced life expectancy, which should accelerate the decumulation of 
wealth. However, the interaction of health with the requirements of home ownership makes the study of ownership more complex than the study of nonfinancial wealth.

\subsection{Conclusions}

This paper investigated the interaction among health, wealth, and where elderly persons live. We reproduce the finding that wealth and health are strongly related to each other. Wealthier persons live longer and are healthy longer. This interaction is moderated by where elderly persons live. Remaining in the lowest wealth quartile is most likely when an elderly person lives in a nursing home and least likely when this person lives with others. The reversed pattern is true for the probability of remaining in the highest wealth quartile. For the initially wealthy, living with others decreases the expected future wealth relative to living alone. This is consistent with the notion that cohabitation implies intrafamily transfers to the needy. For those who remain living independently, home ownership declines, but the speed of reduction is slower than we would expect for financial wealth.

Results in this paper are descriptive and imply no causality. Further research will apply more sophisticated econometric methods in order to identify patterns of causality.

\section{References}

Ai, C., J. Feinstein, D. McFadden, and H. Pollakowski. 1990. The dynamics of housing demand by the elderly: User cost effects. In Issues in the economics of aging, ed. D. Wise, 33-88. Chicago: University of Chicago Press.

Börsch-Supan, A. 1988. Household dissolution and the choice of alternative living arrangements. In The economics of aging, ed. D. Wise, 119-50. Chicago: University of Chicago Press.

Börsch-Supan, A. 1990. Elderly Americans: A dynamic analysis of household dissolution and living arrangement transitions. In Issues in the economics of aging, ed. D. Wise, 89-120. Chicago: University of Chicago Press.

Börsch-Supan, A., V. Hajivassiliou, L. Kotlikoff, and J. Morris. 1992. Health, children, and elderly living arrangements: A multiperiod-multinominal probit model with unobserved heterogeneity and autocorrelated errors. In Topics in the economics of aging, ed. D. Wise, 79-108. Chicago: University of Chicago Press.

Börsch-Supan, A., L. Kotlikoff, and J. Morris. 1991. The dynamics of living arrangements of the elderly, health and family support. In The economics of care of the elderly, ed. J. Pacolet and C. Wilderom, 114-36. Aldershot, England: Avebury.

Börsch-Supan, A., D. McFadden, and R. Schnabel. 1996. Living arrangements, health and wealth effects. In Advances in the economics of aging, ed. D. Wise, 193-218. Chicago: University of Chicago Press.

Costa, D. L. 1997. A house of her own: Old age assistance and the living arrange- 
ments of older nonmarried women. NBER Working Paper no. 6217. Cambridge, MA: National Bureau of Economic Research.

Cox, D., and F. Raines. 1985. Interfamily transfers and income redistribution, horizontal equity, uncertainty and economic well-being. In Horizontal equity, uncertainty, and economic well-being, ed. Martin David and Tim Smeeding, 393421. Chicago: University of Chicago Press.

Ellwood, D. T., and T. J. Kane. 1990. The American way of aging: An event history analysis. In Issues in the economics of aging, ed. D. Wise, 121-48. Chicago: University of Chicago Press.

Grad, S. 1994. Income of the population 55 or older, 1992. pub. no. SSA 13-11871. Social Security Administration, U.S. Department of Health and Human Services. Washington, DC: U.S. Government Printing Office.

Henretta, J. C., M. S. Hill, W. Li, B. J. Soldo, and D. A. Wolf. 1997. Selection of children to provide care: The effect of the earlier parental transfers. The Journals of Gerontology Series B (52B): 110-19.

Horowitz, A. 1985. Family caregiving to the frail elderly. In Annual review of gerontology and geriatrics, ed. C. Eisdorfer, M. P. Lawton, and G. L. Maddox, 194246. New York: Springer.

Hoynes, H. W., M. D. Hurd, and H. Chand. 1998. Household wealth of the elderly under alternative imputation procedures. In Inquiries in the economics of aging, ed. D. Wise, 229-57. Chicago: University of Chicago Press.

Hoynes, H. W., and D. McFadden. 1998. The impact of demographics on housing and non-housing wealth in the United States. In The economic effects of aging and the United States and Japan, ed. M. Hurd and N. Yashiro, 153-94. Chicago: University of Chicago Press.

Hurd, M. D. 1989. Mortality risk and bequests. Econometrica 57 (4): 779-813.

1990. Issues and results from research on the elderly, economic status, retirement, and savings. Journal of Economic Literature 28:565-637.

Hurd, M. D., and D. McFadden. 1998. Predictors of mortality among the elderly: Wealth, income, education and subjective survival probabilities. Paper presented at the American Economic Association Annual Meeting. 3-5 January, Chicago.

Hurd, M. D., D. McFadden, and A. Merrill. 1998. Healthy, wealthy and wise? Socioeconomic status, morbidity and mortality among the elderly. University of California, Berkeley, Department of Economics. Mimeograph, April.

Hurd, M. D., and J. P. Smith. 2002. Expected bequests and their distribution. NBER Working Paper no. 9142. Cambridge, MA: National Bureau of Economic Research.

Kotlikoff, L. J., and J. Morris. 1989. How much care do the aged receive from their children? A bimodal picture of contact and assistance. In The economics of aging, ed. D. Wise, 151-76. Chicago: University of Chicago Press.

. 1990. Why don't the elderly live with their children? A new look. In Issues in the economics of aging, ed. D. Wise, 149-72. Chicago: University of Chicago Press.

McGarry, K., and R. F. Schoeni. 1998. Social Security, economic growth and the rise in independence of elderly widows in the 20th century. RAND Labor and Population Program Working Paper Series no. 98-01. Santa Monica, CA: RAND.

Moon, M. 1983. The role of the family in the economic well-being of the elderly. The Gerontologist 23:45-50.

Rohwedder, S., S. Haider, and M. Hurd. 2004. Increases in wealth among the elderly in the early 1990s: How much is due to survey design? NBER Working Paper no. 10862. Cambridge, MA: National Bureau of Economic Research. 
Sheiner, L., and D. Weil. 1992. The housing wealth of the aged. NBER Working Paper no. 4115. Cambridge, MA: National Bureau of Economic Research.

Skinner, J. 1996. Is housing wealth a sideshow? In Advances in the economics of aging, ed. D. Wise, 214-74. Chicago: University of Chicago Press.

Sloan, F. A., and M. W. Shayne. 1993. Long-term care, Medicaid, and impoverishment of the elderly. Milbank Memorial Fund Quarterly 71 (4): 575-97.

Smith, J. P. 1997. Wealth inequality among older Americans. The Journals of Gerontology Series B (52B): 74-81.

Soldo, B., M. D. Hurd, W. Rodgers, and R. Wallace. 1997. Asset and health dynamics among the oldest old: An overview of the AHEAD study. The Journals of Gerontology Series B (52B): 1-20.

Stone, Robyn, Gail Lee Cafferata, and Judith Sangl. 1987. Caregivers of the frail elderly: A national profile. The Gerontologist 27 (5): 616-26.

Venti, S., and D. Wise. 1990. But they don't want to reduce housing equity. In Issues in the economics of aging, ed. D. Wise, 13-32. Chicago: University of Chicago Press.

. 2001. Aging and housing equity: Another look. NBER Working Paper no. 8608. Cambridge, MA: National Bureau of Economic Research.

Wolf, D. A. 1984. Kin availability and the living arrangements of older women. Social Science Research 13:72-89.

1994. The elderly and their kin: Patterns of availability and access. In Demography of aging, ed. L. G. Martin and S. A. Preston, 146-94. Washington, DC: National Academy Press.

1995. Changes in the living arrangements of older women: An international study. The Gerontologist 35 (6): 724-31.

Wolf, D. A., V. Freedman, and B. J. Soldo. 1997. The division of family labor: Care for elderly parents. The Journals of Gerontology Series B (52B): 102-9.

\section{Comment Steven F. Venti}

Whether elderly persons live independently, live with others, or live in an institution has important implications for their well-being. There seems little doubt that the choice of living arrangements is closely related to the past financial resources and the health status of elderly persons. It is also likely that living arrangements will have an effect on future health and, possibly, wealth as well. Disentangling the complicated relationships between these outcomes is a formidable task. This paper takes a modest first step by carefully describing the relationships among some of the key variables that affect the well-being of the elderly without delving into the complex problem of identifying causality.

The first part of this paper describes how the "state" variables - health (prevalence, incidence, and self-reported measures), wealth (four quar-

Steven F. Venti is a professor of economics and the DeWalt Ankeny Professor of Economic Policy at Dartmouth College, and a research associate of the National Bureau of Economic Research. 
tiles), home ownership, living arrangements (alone, with other, nursing home), and survival—evolve after retirement. This is done by estimating first-order transition probabilities among the state variables, controlling for a set of exogenous variables. The authors are up-front about the limitations of this procedure. There is no claim of causality in the estimated relationships. The use of a first-order process leads to a mechanical tendency for the simulated age profiles to converge over time, so in many simulations the rate of convergence is more important than the level at which simulated profiles eventually converge. The first-order assumption also imposes conditional independence over time. Thus, for example, ownership in the current period, but not length of tenure in an owned home (ownership in previous periods), affects outcomes in the next period. The assumption also implies that a health "shock" will only have a one-period direct effect on other outcomes, although indirect effects may persist through effects on other state variables.

Despite these limitations, the estimates and simulated trajectories based on the estimates provide a rich description of the relationship between the state variables. Given the number of state and control variables, there are almost an infinite number of scenarios the authors could simulate. The key scenarios of interest involve living arrangements - both the effects of other variables on living arrangements and how living arrangements affect other outcomes. The parameter estimates suggest strong persistence of living arrangements: previous location strongly predicts current location. However, there are other significant factors that can lessen this persistence. Marriage is associated with higher rates of ownership and lower rates of the other arrangements. Death of a spouse or a decline in health produces the opposite result. Wealth is positively related to ownership but is unrelated to the likelihood of other living arrangements. None of this is much of a surprise; it implies that healthy, wealthy persons with stable family structures are more likely to own and to continue owning.

Sections 8.2 through 8.4 simulate the interactions between health, wealth, and living arrangements by fixing the control variables, setting initial values of state variables, and letting these state variables vary freely in subsequent periods. Essentially, this procedure allows for complete interaction among the state variables. First is the age profile of home ownership by wealth. Elderly households with lower initial wealth discontinue ownership at a faster rate than elderly households with high initial wealth. It is important to emphasize that state variables, such as the incidence of a health problem or nursing home entry, are not held constant in the simulated age profile of ownership. Thus, low-initial-wealth households end up with lower rates of ownership than high-initial-wealth households, but other state variables may be indirectly responsible for the decline.

Another issue to keep in mind is that the parameter estimates are average effects. A conditional logit of ownership in the current period on own- 
ership and other state variables in the previous period is the basis for the simulated age-profile of ownership. This methodology yields the average ownership profile in the population. Of course, it may be that few individuals behave like an "average" person, particularly when many of the state variables, such as ownership, are discrete. Thus, the authors' observation that "home ownership declines slowly but steadily as people age" is a description of average behavior but not necessarily of individual behavior. We will return to this point.

Another set of simulations considers the trajectory of wealth for households with different initial living arrangements. Again, full interaction among the state variables is allowed. Households initially in nursing homes are more likely to remain poor, and households initially living with others are least likely to remain poor. The probability of remaining poor for all three living arrangements decreases from ages seventy to eighty-five and then begins to rise. Perhaps a large fraction of initially poor householdsregardless of their initial living arrangement - eventually face the financial burden of nursing home costs. This peculiar result deserves further analysis.

Perhaps the most interesting results pertain to the effect of the control variables. As expected, marriage and home ownership are positively related. The sex composition of children is startlingly powerful. Having daughters substantially increases the likelihood of living with others and decreases the probability of other living arrangements.

To isolate the effects of individual state variables, the authors fix some of the state variables at their initial values and let the others vary. The simulations consider survival and wealth trajectories when some of the health variables are fixed. As expected, the probabilities of remaining alive and remaining in the highest wealth quartile are higher when persons are assumed to remain healthy. This technique is useful to sort out the relationships between the state variables, but unfortunately it is not applied to either home ownership or living arrangements. A final set of simulations looks at the effect of health shocks on age profiles for survival and selfreported health status.

The second part of the paper shifts the focus to a more detailed analysis of the decline in home ownership. This has been widely studied (Merrill 1984; Sheiner and Weil 1992; Feinstein and McFadden 1989; Venti and Wise 1990, 2004; Megbolugbe, Sa-Adu, and Shilling [1997]), and the results are broadly consistent: households that experience shocks such as death of a spouse, change in health, or nursing home entry have a higher likelihood of discontinuing ownership. Elderly households that do not experience these shocks tend to stay put and may even increase home equity on average. For example, Venti and Wise (2004), also using the AHEAD, find annual percentage declines in home equity (not ownership) of 0.1 percent among continuing two-person households, 1.2 percent among con- 
tinuing one-person households, and 7.8 percent among households that suffer the death of a spouse or in which a member enters a nursing home. Among all households combined, the decline in home equity is 1.8 percent per year.

The results in this paper are broadly consistent with these findings. The projected rate of home ownership for married couples declines from 100 percent to 75 percent between the ages of seventy and ninety, or about 1.4 percent per year. For continuously single households the projected annual rate of decline is 3.4 percent. The overall rate of ownership decline for all households is about 2.5 percent per year. These estimates are slightly higher than the Venti-Wise estimates, but there are three important differences. First, the Venti-Wise estimates pertain to home equity, so rising real house prices as well as declining mortgage balances suggest that equity will fall more slowly than ownership. Second, the studies also differ in their treatment of households in which a member entered a nursing home. These households have a very high rate of exit from ownership. The Venti-Wise estimates for one-person and two-person households exclude these nursing home entrants and are expected to be lower. Finally, the changes in home equity reported by Venti-Wise include not only the decline in home equity among households that discontinue owning, but also the change in home equity among initial owners who buy another home. On average, this latter group of owners "trades up," thus offsetting, in part, the decline in equity for households moving out of ownership. In light of these differences, the authors' overall rate of ownership decline for all households of about 2.5 percent per year is of comparable magnitude to the 1.8 percent per year decline in home equity found by Venti and Wise. Interestingly, the logit estimates presented in table 8.9 show that significant reductions are associated with death of a spouse and incidence of a health event (as well as initial housing and nonhousing wealth quartiles), but once these shocks are accounted for, there is no tendency for ownership to decline with age.

Although the authors' empirical results are consistent with prior findings, the interpretation of these results is not. The authors compare their findings to the rate of decumulation predicted by the life-cycle model and to observed rates of decumulation of nonhousing wealth. They hope to establish "whether the path of ownership as an indicator of housing wealth is broadly consistent with wealth paths predicted by the LCM." The authors compare their ownership projections to wealth change in the 198485 SIPP, to the subjective probability of bequests elicited in the HRS, and to the predicted path of bequeathable wealth based on a life-cycle model using data from the 1969-79 Retirement History Survey. The authors conclude that their results are "broadly consistent" with these wealth paths, although it is clear that the decline in ownership in the AHEAD is less pronounced than any of the three comparison wealth profiles.

I find it odd that the authors compare the decline in home ownership ob- 
tained from the 1992-98 AHEADs to declines in wealth estimated from the 1984 SIPP and the 1969-79 Retirement History Survey. More recent data are available for this comparison. The 1996 panel of the SIPP shows little decline in nonhousing wealth through age eighty (authors' estimates), and the AHEAD shows dramatically increasing nonhousing wealth among the older old (Hurd 2002). The authors are aware of the AHEAD results but argue that "the 1995 wave of AHEAD was followed by the stock market boom, leading to wealth increases that were likely unanticipated, and do not reflect planned life-cycle wealth accumulation."

The same reasoning can be used to argue that the decline in home ownership observed in the AHEAD does not reflect life-cycle motives. Most, or perhaps all, of the decline in ownership is accounted for by changes in health status or the death of a spouse. Elderly households that do not face these shocks (likely unplanned and unanticipated) decumulate very little of their housing wealth, if any. This suggests that most elderly persons desire to continue owning their homes for as long as they can. In the absence of shocks, housing wealth is not used to finance general consumption in retirement, as implied by the LCM. This unwillingness to downsize may be rooted in emotional and psychological attachment to homes, or it may reflect the conscious decision to keep the house as a form of insurance against catastrophic events. Survey evidence suggests that, with the possible exception of an end-of-life hospital stay, the members of most households plan, desire, and expect to die in their homes (American Association of Retired Persons 2000). Their "plan" is not to decumulate housing wealth, and, for the large fraction of the population that does not experience these events, the decline in ownership looks nothing like the profile predicted by the LCM. Of course, some fraction of the population experiences some sort of shock, and these households decumulate dramatically. Thus, as noted earlier, the "average" profile may bear some resemblance to a life-cycle path, but the experience of individual households does not.

Overall, this paper is a promising start to disentangling the complicated relationship between health, wealth, and living arrangements. The relationships are so complicated that it is difficult to even develop a methodology to describe them in a systematic and coherent way. The vector autoregression structure used here does quite a good job. The initial results are informative, although I yearn for more simulations of ownership and living arrangements that hold fixed other outcomes. Such simulations help to isolate the effects of these key state variables. I look forward to further efforts to extend this methodology.

\section{References}

American Association of Retired Persons. 2000. Fixing to stay: A national survey of housing and home modification issues. Washington, DC: AARP. 
Feinstein, J., and D. McFadden. 1989. The dynamics of housing demand by the elderly: Wealth, cash flow, and demographic effects. In The economics of aging, ed. D. Wise, 55-86. Chicago: University of Chicago Press.

Hurd, M. 2002. Portfolio holdings of the elderly. In Household portfolios, ed. L. Guiso, M. Haliassos, and T. Jappelli, 431-71. Cambridge: MIT Press.

Megbolugbe, I., J. Sa-Aadu, and J. Shilling. 1997. Oh, yes, the elderly will reduce housing equity under the right circumstances. Journal of Housing Research 8 (1): $53-74$.

Merrill, S. 1984. Home equity and the elderly. In Retirement and economic behavior, ed. H. Aaron and G. Burtless, 197-238. Washington, DC: Brookings.

Sheiner, L., and D. Weil. 1992. The housing wealth of the aged. NBER Working Paper no. 4115. Cambridge, MA: National Bureau of Economic Research.

Venti, S., and D. Wise. 1990. But they don't want to reduce housing equity. In Issues in the economics of aging, ed. D. Wise, 13-32. Chicago: University of Chicago Press.

- 2004. Aging and housing equity: Another look. In Perspectives on the economics of aging, ed. D. Wise, 127-80. Chicago: University of Chicago Press. 